\title{
SOBRE LA VIGENCIA EN MÉXICO DE LA CONSTITUCIÓN ESPAÑOLA DE CÁDIZ DE 1812
}

\author{
JOSÉ BARRAGÁN
}




\section{SUMARIO}

1. PRESENTACIÓN DEL TEMA. 1.1 Primera vigencia de la constitución de 1812. 1.2. Según la llamada Constitución de Apatzingán de 1814. 1.3. El regreso al Antiguo Régimen. 1.4. La nueva vigencia durante el Trienio Liberal; 1.5. La vigencia decretada por el Plan de Iguala. 1.6. Vigencia decretada por la Soberana Junta Provisional Gubernativa. 1.7. La vigencia decretada por el primer Congreso constituyente mexicano. 1.8. La vigencia decretada por el segundo Congreso constituyente mexicano. 1.9. La vigencia decretada hacia el interior de los Estado. 1.10. Sobre los cuerpos de leyes declarados en vigor. 2. SU CONSOLIDACIÓN EN LAS INSTITUCIONES LOCALES. 2.1. El punto de partida. 2.2. Las 19 constituciones de referencia. 2.3. Siguiendo el modelo de la Constitución gaditana. 3. A MODO DE CONCLUSIÓN. 4. FUENTE CONSULTADA. 


\title{
SOBRE LA VIGENCIA EN MÉXICO DE LA CONSTITUCIÓN ESPAÑOLA DE CÁDIZ DE 1812
}

\author{
JOSÉ BARRAGÁN \\ Universidad de Guadalajara
}

\section{PRESENTACIÓN DEL TEMA}

Al hablar de la Historia del Derecho en México, es común ver cómo se hace el esfuerzo por estudiar lo que se suele llamar el Derecho de los diferentes pueblos aborígenes, asentados sobre la geografía de nuestro país. Desde luego, también se hace el esfuerzo por estudiar el llamado Derecho Indiano, dictado desde la misma metrópoli de Madrid, durante la etapa colonial.

Y, llevados por las creencias revolucionarias, aún los abogados y los especialistas llegan a pensar que, por efecto del levantamiento armado y, en todo caso, por efecto de la misma declaración de independencia, se rompen todos los lazos con dicho Imperio.

Se está, por tanto, en la creencia de que es el Derecho, o de que a través de las normas jurídicas es como se materializa la opresión del conquistador sobre los pueblos sometidos y que éstos, una vez adquirida su libertad, gustosamente regresarán a gobernarse por el Derecho originario que en cada caso hayan tenido.

¿Qué es lo que realmente ocurre en el caso mexicano? ¿Cuál es el Derecho que se declara en vigor, incluso por obra de la llamada Constitución de Apatzingán, o constitución de la insurgencia mexicana de 1814 y, después por boca de las autoridades que fueron sustituyendo a las españolas?

Invitamos al lector a seguirnos en el siguiente planteamiento, que de alguna manera es efecto de los diferentes trabajos emprendidos por su servidor sobre la vigencia en México de la Constitución española de Cádiz y de otros muchos decretos aprobados por aquellas Cortes. 
Miguel Guridi y Alcocer, durante la sesión del día 22 de noviembre de 1823 de la llamada Junta Nacional Instituyente, decía que la Constitución de 1812 era una constitución nuestra, porque había sido firmada por los diputados mexicanos presentes al ser aprobada y la consideraba digna, porque algunos de los defectos que contenía, ya habían sido subsanados por el Plan de Iguala y el Tratado de Córdoba de 1821.

Los defectos a que se refería don Miguel Guridi y Alcocer eran los de no haber abolido la esclavitud y las limitaciones impuestas en materia de ciudadanía.

Por su efectiva vigencia durante los períodos en que la sostuvieron las Cortes de Cádiz, esto es, hasta antes de la llegada de don Fernando VII a Valencia en 1814; y su vigencia durante los años de 1820 y 1821 en que fue nuevamente jurada en España; y, desde luego, por sus méritos intrínsecos dicha Constitución fue declarada como constitución provisional por las autoridades mexicanas de esa primera etapa de nuestra independencia, así como hacia el interior de cada uno de los 19 Estados miembros de la Federación mexicana, formalizada mediante la firma de su Acta constitutiva del día 31 de enero de 1824, en todo aquello que no se opusiera al estado de cosas que se iban creando.

Debido al curso de los acontecimientos y a cierta falta de interés, tal vez ocasionada por la vuelta al Antiguo Régimen en España y al desprendimiento de las colonias americanas al alcanzar su independencia, la obra de aquellas Cortes no ha sido ni suficientemente conocida ni suficientemente valorada.

Como quiera que sea, la impresión de su servidor es la de imaginar que las Cortes de Cádiz trabajaron especialmente para México, precisamente para consolidar su aventura independentista con la adopción del modelo de Estado moderno, alzado sobre los principios de la nacionalización del poder político y del poder económico, por efecto, desde luego, del decreto de supresión de los señoríos; un Estado fuerte y liberal, republicano y federal.

\subsection{Primera vigencia de la constitución de 1812}

Como se sabe, en la Nueva España no prosperó la insurgencia independentista, ni bajo el proceso de formación de juntas hacia el año de 1808, tal como sucedió en el Reino de la Nueva Granada, ni bajo la bandera de la insurgencia armada de don Miguel Hidalgo y de don José María Morelos hacia el año de 1810. Ambas cosas fracasaron y fueron reprimidas por las fuerzas leales a España, las cuales ciertamente facilitaron la entrada en vigor de los decretos y de las órdenes emanadas de las Cortes de Cádiz. 
Así pues, jurada ${ }^{1}$ la Constitución de 1812, la organización territorial y política se conformó según lo establecido por dicha Constitución. Es decir, siguiendo lo establecido, por un lado, en el artículo 10 y 11; y, por otro lado, según lo disponía el título VI de la misma Constitución, desde el artículo 309 al 337.

En el artículo 10, en efecto, se mencionan los territorios de la Nueva España, de la Nueva Galicia y de la Península de Yucatán. A continuación, el artículo 11, indica que una ley constitucional hará una división más conveniente del territorio español.

Todo el territorio español, en efecto, se dividirá en provincias, a cuyo frente estará un órgano colegiado denominado Diputación Provincial, y éstas en municipios, teniendo la organización política interna de los ayuntamientos, según se establece en el título VI de la misma Constitución, del artículo 309 al 337 el territorio español se dividirá en provincias, a cuyo frente estará un órgano colegiado denominado Diputación Provincial; y éstas, en municipios, teniendo la organización interna de los ayuntamientos.

Dura poco tiempo la vigencia de esta Constitución, ya que don Fernando VII, al llegar a Valencia en 1814, resolvió anular la obra de las Cortes de Cádiz, para restablecer el sistema del llamado Antiguo Régimen, período éste que llega hasta el levantamiento del General Riego en 1820, quien obliga al Rey don Fernando VII al restablecimiento de la Constitución de Cádiz, abriéndose así la etapa histórica del Trienio Liberal.

\subsection{Según la llamada Constitución de Apatzingán de 1814}

Mientras don Fernando VI imponía el sistema del Antiguo Régimen, el movimiento insurgente mexicano alcanzó a expedir la llamada Constitución de Apatzingán, aprobada el 24 de octubre de 1814.

Conocemos bien la forma en que la Constitución de Apatzingán dividía el territorio de la llamada América mexicana, a saber, en 17 provincias; y éstas se dividían en municipios.

Decía el artículo 208 que en los pueblos, villas y ciudades continuarán respectivamente los gobernadores y repúblicas, los ayuntamientos y demás empleos, mientras no se adopte otro sistema.

Esto es, por un lado se respeta la organización de provincias y municipios y se menciona de manera especial para ser igualmente respetados y conservados, el go-

${ }^{1}$ El Archivo General de la Nación publicó en 1912 diversos testimonios sobre la forma en que fue jurada dicha Constitución de Cádiz en la Nueva España. Esta publicación lleva el título de La Constitución de 1812 en la Nueva España, México, 1912. 
bierno de los pueblos aborígenes, por medio de sus gobernadores, y las así llamadas repúblicas.

\subsection{El regreso al Antiguo Régimen}

Dentro de este mismo período, debemos mencionar la vuelta al Antiguo Régimen decretada en 1814 a su regreso y paso por Valencia por don Fernando VII.

\subsection{La nueva vigencia durante el Trienio Liberal}

Ahora bien, como recordamos, de nueva cuenta vuelve a jurarse el texto de la Constitución de Cádiz, que se vuelve a poner en vigor a partir del alzamiento del general Riego en 1820.

Esta vigencia se impone también en México, de manera que, entre otras cosas, se restablece la organización política prevista en dicha Constitución doceañista; y se convoca a elecciones para elegir diputados a las Cortes ordinarias de Madrid para ese mismo año de 1820.

\subsection{La vigencia decretada por el Plan de Iguala}

Vigente la Constitución de Cádiz, entra en escena don Agustín de Iturbide, quien, antes que nada, emite una proclama conocida como Plan de Iguala, el día 24 de febrero de 1821, en cuyo articulado, se declaran subsistentes todos los ramos del Estado y empleados públicos y se recuerda que, en materia de delitos, éstos serán castigados de conformidad con lo dispuesto por la constitución de 1812, según se dice en el punto 19.

Bien, en su Plan de Iguala, que ya aparece como el primer paso para consolidar la idea de imperio que abrigaba el propio Iturbide, leemos:

«Art. 15. Todos los ramos del Estado y empleados públicos, subsistirán como en el día, y sólo serán removidos los que se opongan a este plan.» ${ }^{2}$

A continuación el artículo 20 decía:

«Art. 20. Interim se reúnen las Cortes, se procederá en los delitos con total arreglo a la Constitución española.» ${ }^{3}$

${ }^{2}$ Véase a Isidro Antonio Montiel y Duarte, Derecho Público Mexicano, ya citado. Tomo I. p. 47.

${ }^{3}$ Véase en la misma obra, ya citada, Tomo I. p. 47. 
No se hace tampoco ninguna novación respecto al cuerpo de leyes que deben observarse en México después de expresar el rompimiento con España, sino hasta en tanto se reunían las Cortes mexicanas, de conformidad con las previsiones de dicho Plan.

De hecho, el propio Iturbide pasará a formar una Junta especial que lleva el nombre oficial de Soberana Junta Provisional Gubernativa, compuesta por grandes personalidades y que recibiría el encargo de elaborar y aprobar la convocatoria para reunir dichas Cortes mexicanas con el carácter de constituyentes.

Hasta este momento, los pueblos centroamericanos han permanecido atentos nada más respecto de lo que estaba ocurriendo en México, sobre todo atentos a los movimientos y las actuaciones del propio Iturbide, sin externar nada en particular salvo la entusiasta voluntad de alcanzar la independencia, como lo expresan las diferentes declaraciones que se hacen en tal sentido.

Ahora bien, instalada la Soberana Junta Provisional Gubernativa y al entrar en el debate de la ley de convocatoria de un Congreso Constituyente que organice al país bajo la forma de un Imperio, claramente se advierte la intención de llamar a todos los pueblos centroamericanos para formar parte de este gran Imperio.

En efecto, la convocatoria es abierta. Y de hecho hubo elecciones, no sólo en el llamado Reino de México, sino también en el llamado Reino de Guatemala, que es como se expresarán los propios diputados reunidos por esta convocatoria a partir del 24 de febrero de 1822.

Bien, hecha esta advertencia, sobre la cual luego volveremos, veamos el sentido que tienen las declaraciones de vigencia hechas por esta Soberana Junta Provisional Gubernativa.

\subsection{Vigencia decretada por la Soberana Junta Provisional Gubernativa}

Dicha Junta empezó a sesionar el día 22 de septiembre del mismo año de 1821 y se tuvo siempre como soberana, en los términos en que las Cortes generales y extraordinarias de Cádiz lo habían sido, ya que, entre otros extremos, se conducen con apego al reglamento que se dieron aquellas Cortes en 1810, ligeramente adecuado para México.

Así pues, a pocos días de haber iniciado sus trabajos, esta Junta aprobó un decreto el día 5 de octubre del mismo año de 1821, en el que encontramos los siguientes pronunciamientos:

«La Soberana Junta Provisional Gubernativa del imperio mexicano, considerando que desde el momento en que decretó solemnemente su independencia de España, debe emanar del mismo imperio, toda la autoridad que necesita para el 
ejercicio de la administración de justicia y demás funciones públicas, ha tenido a bien habilitar y confirmar a todas las autoridades en calidad de por ahora, y con arreglo al Plan de Iguala y Tratados de la Villa de Córdoba, para la legitimidad del ejercicio de sus funciones respectivas.» ${ }^{4}$

Tenemos ante nosotros una solemne como expresa habilitación de instituciones y autoridades para que continúen laborando y ejerciendo su respectivo ministerio de conformidad con las leyes hasta entonces en vigor.

Ahora bien, como bien sabemos, la organización existente, es la organización impuesta por la Constitución de Cádiz, de manera que la referida rehabilitación es para que las tales autoridades y tal organización siguiera trabajando con total apego a las leyes gaditanas, antes que nada.

Como vemos, aquí están presentes, no sólo las ideas revolucionarias de proceder de inmediato a operar los cambios institucionales que fueran necesarios, sino también a renovar todo el cuerpo de leyes para que emanaran del mismo imperio, en palabras de este decreto.

Así pues, ya fuera por el efecto natural del regreso de la implantación de la Constitución de Cádiz en 1820, o ya fuera, particularmente en México, por efecto del mismo regreso de dicha Constitución, así como por el aval otorgado por las declaraciones de esta Soberana Junta, se obtuvo una verdadera consolidación de las instituciones gaditanas.

\subsection{La vigencia decretada por el primer Congreso constituyente mexicano}

La Soberana Junta Provisional Gubernativa cumplió su encomienda y antes de disolverse, dejó instalado lo que es para México, (y probablemente también para cada uno de los países de Centro América) el primer Congreso Constituyente Mexicano, en palabras de su libro de Actas, reunido el día 24 de febrero de 1822. Como lo hicieran las Cortes españolas de Cádiz, éste Congreso hace unos precisos pronunciamientos, muy solemnes y de la mayor importancia ese mismo día 24 de febrero de $1822 .^{5}$

A saber, que se encuentra instalado legítimamente como Congreso constituyente; que la soberanía residía en la nación mexicana; que también reside dicha soberanía en este Congreso constituyente y que:

\footnotetext{
${ }^{4}$ Véase en la misma obra, ya citada, Tomo I, p. 219 y 220. Dichos Tratados en su artículo 12 indican que la misma Junta Provisional Gubernativa gobernará conforme a las leyes vigentes.

${ }^{5}$ Véase su libro de Actas, cuya edición fue preparada por su servidor en Colección de Actas Constitucionales Mexicanas 1821-1824, UNAM, 1920. La cita en el tomo 2.
} 
«... delegando interinamente el ejercicio del Poder Ejecutivo en las personas que componen la actual Regencia y el judiciario en los Tribunales que actualmente existen, o que se nombren en adelante, quedando unos y otros cuerpos responsables ante la nación por el tiempo de su administración con arreglo a las leyes.» ${ }^{6}$

Poco después, el día 26 el mismo congreso emitió un decreto diciendo que:

«El soberano Congreso Constituyente Mexicano confirma por ahora a todos los tribunales y justicias establecidos en el imperio, para que continúen administrando justicia según las leyes vigentes.» ${ }^{7}$

¿Qué tenemos detrás de estas solemnes declaraciones?

La vigencia de la Constitución de Cádiz es real y efectiva, en todas sus partes y en todos los rincones de aquella enorme geografía. Las elecciones se hicieron tomando en cuenta la regulación prevista en dicho texto; la división política y territorial que existe, es la impuesta por el texto gaditano y, por lo mismo, todas las autoridades existentes, son las autoridades previstas en ese mismo texto gaditano; en suma, toda la legislación vigente es esta misma que venimos viendo que es declarada en vigor.

Este primer Congreso hizo propio para su gobierno interior el Reglamento de las Cortes de Cádiz de 1813 y condujo sus sesiones de conformidad con las disposiciones de la mencionada Constitución doceañista, según lo explicamos nosotros con detalle en nuestro libro Introducción federalismo: la formación de poderes:1824, publicado por la Universidad Nacional Autónoma de México en 1978.

\subsection{La vigencia decretada por el segundo Congreso constituyente mexicano}

Se trata del Congreso que preparó y aprobó la Acta constitutiva de la Federación del 31 de enero de 1824 y, desde luego, aprobó la primera constitución mexicana del 4 de octubre de 1824 .

Por lo que hace a nuestro tema, resulta que durante la sesión del día 2 de enero de 1824 y discutiéndose un artículo adicional, para que figurase como facultad cuarta de las del congreso general, la de proteger y arreglar la libertad de imprenta, Zavala hizo la siguiente pregunta: si se entendía quedar derogada por el Acta constitutiva toda la constitución española, pues en tal caso era necesario añadirle muchas cosas, y de lo contrario podía omitirse la facultad de que se menciona.

\footnotetext{
${ }^{6}$ Véase, entre otras fuentes, en Isidro Antonio Montiel y Duarte, Derecho Público Mexicano, ya citado, Tomo I, p. 228.

${ }^{7}$ En la misma obra de Isidro Antonio Montiel y Duarte, Tomo I, p. 229.
} 
A continuación, Herrera, diputado por Veracruz contestó textualmente: que de la constitución española debia entenderse derogado lo que fuese contrario al Acta. ${ }^{8}$

Tal vez por ello, por considerar que la constitución de Cádiz quedaba en vigor, como legislación supletoria, si así podemos expresarnos, Rodríguez de San Miguel en su Tercera guía judicial, o Colección de leyes de más frecuente uso en la administración de justicia, publicada en México en el año de 1850, le pareció muy correcto incluir ciertos y determinados artículos de aquella constitución sobre diversas garantías de los presos.

Este segundo congreso, para su gobierno interior, también hizo suyo simple y llanamente el Reglamento gaditano del 4 de septiembre de 1813 y después, el propio congreso aprobó, siguiendo muy de cerca el texto gaditano, un reglamento para el gobierno interior del Congreso de la Unión, el cual entró en vigor en diciembre de $1824 \mathrm{y}$, con ligeras modificaciones, estuvo en vigor hasta finales del siglo XIX.

\subsection{La vigencia decretada hacia el interior de los Estados}

Sabemos bien que fueron 19 los Estados que firmaron el Acta constitutiva de la federación mexicana del día 31 de enero de 1824, consolidando así la idea de una organización republicana, de carácter federal, para los mexicanos, después de los fallidos intentos de don Agustín de Iturbide por formar un Imperio.

Tenemos, por tanto, 19 procesos históricos de formación bajo las características, reconocidas en dicha Acta o Pacto de Unión, de Estados libres independientes y soberanos en todo lo relativo a su régimen interno.

Cada uno de dichos 19 Estados tiene su propia historia de transformación a partir de las estructuras políticas que impuso la vigencia en México de la Constitución española de Cádiz.

Dentro de esa historia particular, debemos situar la libre declaración de cuáles tenían que ser las leyes debían observarse hacia el interior de su régimen soberano.

Nosotros ahora, como es natural, no vamos a citar las declaraciones de vigencia que en cada caso se hacen, por la evidente limitación del presente artículo. Sin embargo, sí intentaremos darle una idea cabal al lector, al citarle algunos ejemplos, dentro del contexto que se crea por la sucesiva aparición de cada una de esas 19 constituciones.

${ }^{8}$ Véase en Crónicas del Acta constitutiva, edición de la H. Cámara de diputados, México, 1974. Preparación, Introducción y notas de José Barragán. La cita en p. 
A) En el caso de Jalisco

En relación con nuestro tema, véase el Plan Provisional de 21 de junio de 1823, así como los primeros decretos emitidos por su Constituyente.

En ellos vemos que, primero, se confirma a todas las autoridades civiles, eclesiásticas y militares para que continúen ejerciendo sus funciones en tanto no se opusieran al nuevo estado de cosas creado por los pronunciamientos de convertirse en un Estado libre e independiente.

Después se declara como Constitución propia, mientras se emite la particular del Estado, a la Constitución de 1812 y la vigencia de todos los demás cuerpos de leyes españolas, en todo aquello que no pugne con el presente Plan, se dice. ${ }^{9}$

Art. 18. El Estado se gobernará por la Constitución española y leyes vigentes, en todo aquello que no pugne con el presente Plan.

Además y respecto del poder judicial y los ayuntamientos se dice:

Art. 16.-El Poder Judicial del Estado, se ejercerá por las autoridades hasta abora establecidas. El Tribunal de la Audiencia determinará en el último recurso en la respectiva sala los asuntos judiciales del Estado, correspondientes a la jurisdicción ordinaria.

Art.17. Los ayuntamientos y demás corporaciones y autoridades, tanto civiles, como militares y eclesiásticas, continuarán desempeñando las funciones que les están cometidas.

B) En el caso de Oaxaca

El Estado de Oaxaca empezó, como Jalisco, su proceso de transformación hacia el mes de junio del mismo año de 1823. Como ocurrió en toda la Nueva España, la organización de esta Provincia se correspondía al pié de la letra con lo dispuesto por la Constitución de Cádiz y la legislación española emanada de las mismas Cortes.

Incluso, por un comentario aparecido en el periódico Águila Mexicana, sabemos que Oaxaca siguió el ejemplo de Jalisco. proclamándose independiente y erigiéndose en República Federal. ${ }^{10}$

${ }^{9}$ Esta materia ha sido estudiada con detalle por nosotros en el libro Introducción al federalismo mexicano, UNAM, México, 1978. El estudio en página 147 y siguientes.

Por ejemplo, la Audiencia de Guadalajara será transformada en el Supremo Tribunal de Justicia del Estado; el Jefe Superior Político, que es Quintanar, fue nombrado primer gobernador provisional del nuevo Estado de Jalisco. Tampoco los ayuntamientos sufren modificación alguna.

${ }^{10}$ En Aguila Mexicana del 11 de junio de 1823. 
El primer día del mes de junio de 1823 tuvieron lugar en Antequera, las reuniones y manifestaciones típicas del pronunciamiento a favor de la República federal y de separación de México.

La Diputación encabeza las aspiraciones populares. Se nombra Junta Superior Gubernativa. Y ante la masa popular, repetimos, autoridades civiles y militares, acordaron hacer uso de su natural e indispensable soberanía, ${ }^{11} y$, entre otros puntos, se aprobaron las bases provisionales con que se emancipó la provincia de Oaxaca, como reza el epígrafe periodístico del Águila del día once de junio. He aquí los puntos principales:

2. En orden a su soberanía, la ejerce exclusiva y federalmente;

3. Para el ejercicio de tales funciones, instalará un congreso provincial que la constituya sobre las bases precisas de libertad, igualdad, propiedad y seguridad.

5. Entre tanto esto se verifica (reunión del congreso), residirá el mando de las armas en el Comandante General de la Provincia y en la Junta Superior Gubernativa, los que abrazan los demás ramos.

8. Las leyes vigentes que no sean opuestas al sistema son precisamente las que rijan hasta que el congreso determine otra cosa.

9. Las providencias que emanen de México, ya no regirán, y a los actuales diputados que allí residen, se les mandará orden para que se retiren sin abonarles dietas por el tiempo de su demora voluntaria.

15. Los enemigos declarados del sistema serán expatriados (sic) de la provincia, previa formación de causa y justificación del delito. ${ }^{12}$

Los motivos aducidos coinciden en el fondo con los expuestos al hablar sobre el pronunciamiento de Yucatán: la Diputación se reúne urgentemente porque peligraba la tranquilidad pública. ${ }^{13}$

Este peligro consistía en que una parte del pueblo quería constituirse en república federada: que por esta indicación se pidió al sr. Gefe político su presencia en ella, para lo que se le envió una comisión, con la que vino y se le dijo que explorase la voluntad de los ciudadanos, gefes, oficiales y tropa de guarnición... ${ }^{14}$

El jefe político se reúne con la tropa y, después de deliberar, se dirige a la Diputación y le dice que: en ella be visto consonante el voto militar con el del pueblo, como

\footnotetext{
${ }^{11}$ Véase Acta de Oaxaca en Águila Mexicana del 23 de junio de 1823.

${ }^{12}$ En Aguila Mexicana del día 11 de junio de 1823.

${ }^{13}$ En dicha Acta, véase en Águila Mexicana del 22 de junio de 1823.

${ }^{14}$ En dicha Acta, pero en Águila Mexicana del 23 de junio de 1823.
} 
lo manifiesta el testimonio de la acta que debidamente acompañó a V.S. para sus deliberaciones. ${ }^{15}$

Esta acta fue firmada por todos los oficiales de la tropa, y se dice que:

«... convencidos de la utilidad, necesidad y conveniencia que en el día se tiene de la separación del gobierno, que desoyendo la opinión general, demostrada por las enérgicas demostraciones de varias provincias, nos pone en la precisión de declararnos por libres de tal dependencia y por consecuencia en aptitud, y resolución de constituirnos por nosotros mismos; sin que por esto se entienda que tal caso nos separa de las imprescriptibles relaciones con que la madre naturaleza nos tiene unidos como ciudadanos de una nación.» ${ }^{16}$

La Diputación continuaba en sesión permanente debido al tumulto popular, que gritaba que no se demorasen dichas resoluciones; que se declarase el gobierno provisional independiente de México, pidiendo que de becho se declare República Federada. En efecto, se aprobó la proposición de que Oaxaca era independiente, y libre absolutamente, constituyéndose en República Federada con todas las demás provincias del Imperio. ${ }^{17}$

El día 3 de junio se comunica en circular el acuerdo tomado a todos los pueblos de la antigua provincia. ${ }^{18} \mathrm{Y}$ el 28 del mismo mes de junio cesaba la Junta, al dejar instalado el Congreso Constituyente, ${ }^{19}$ el cual comenzó a sesionar el día 6 de julio, fecha de su primer Decreto.

Por este Decreto se confirmaba el cese de la Junta Superior (artículo 1); se confirmaba así mismo a todas las autoridades (artículo 2); y la pervivencia de las leyes hasta entonces en vigor (artículo 3).

«Por ahora quedan en su vigor y vigencia la Constitución General y leyes y órdenes y reglamentos que hasta hoy han regido y no se opongan al sistema de independencia y república federal.» ${ }^{20}$

Además se aprobaron las Bases para el gobierno del Estado, en tanto era aprobada la propia Constitución de la Nación y la particular del Estado:

Art. 4. Este Estado es libre y sólo reconocerá con los demás de la nación mexicana las relaciones de fraternidad, amistad, y confederación, que determine la Constitución general.

\footnotetext{
${ }^{15}$ En Águila Mexicana del día 23 de junio de 1823.

${ }^{16}$ Ibidem.

${ }^{17}$ En Águila mexicana, del día 24 de junio de 1823.

${ }^{18}$ En Aguila Mexicana del 9 de julio de 1823.

${ }^{19}$ Manifiesto de la propia Junta, publicado en Águila del día 9 de julio de 1823.

${ }^{20}$ Este caso ha sido estudiado en el mismo libro nuestro, ya mencionado, p. 139
} 
Art. 6. Su gobierno será popular, representativo, federado.

Art. 7. Por abora y hasta el arreglo de la Constitución general de la nación y la particular del Estado, quedan en su vigor y fuerza la Constitución, las leyes, órdenes y reglamentos que hasta boy ban regido y no se opongan al sistema de independencia.

Art. 8. Todas las autoridades continuarán desempeñando las funciones que les estén conferidas.

Art. 11. No se dará la Constitución del Estado hasta que salga la general de la $\mathrm{Na-}$ ción mexicana. ${ }^{21}$

Tal es el arranque político del Estado Libre y Soberano de Oaxaca, siguiendo el ejemplo de Jalisco, como dice el Águila Mexicana del 11 de junio, arriba cita$\mathrm{da}$, dicho que concuerda con una circular de Quintanar, invitando a todas las provincias a constituir congresos provinciales.

Por último, importa añadir que, por un lado, el texto mismo de la Constitución de Oaxaca, al reconocer la subsistencia del fuero eclesiástico y del fuero militar, precisa que ambas clases seguirán sujetas a las autoridades a que lo están en la actualidad, en los términos que prescriben las leyes vigentes, en palabras del el artículo 178 y que, por otro lado, el artículo 180, después de ordenar, para la más puntual administración de justicia, la formación de los códigos, tanto en materia civil como en materia criminal, se observarán las leyes vigentes sobre estas materias.

He aquí muy resumida la forma en que se procede en Oaxaca a la hora de emprender el movimiento de independencia del propio Estado, dejando siempre abierta la puerta para la formación de un gobierno general de carácter federal.

C) En el caso de Yucatán.

La diputación provincial de Yucatán acuerda el día 9 de abril de 1823, un poco más de un mes de reinstalado el Congreso, crear una Junta Provisional Administrativa para hacer observar las leyes, guardar los derechos de los ciudadanos y de dirigir la administración pública, funciones absolutamente necesarias para mantener el orden y tranquilidad general, y evitar las funestas consecuencias de la anarquía. ${ }^{22}$

Se fundamenta y se justifica tan trascendental paso en la falta del Ejecutivo nacional, o al vacío de autoridad. El término de provisional, y las palabras entre-

${ }^{21}$ Las Bases de que habla del Decreto pueden verse en Águila Mexicana del 13 de agosto de 1823.

${ }^{22}$ En Águila Mexicana del 14 de mayo de 1823. 
tanto se forma el supremo gobierno nacional, lo confirma.

Sin embargo, dicho Ejecutivo nacional ya estaba formado, y había jurado su cargo el 31 de marzo, 9 días antes de la fecha del Manifiesto. Quizá la noticia aún no había llegado. A lo mejor, esos motivos, lo eran sólo en apariencia, porque, sin duda, la ausencia de autoridad no era sino relativa. ¡Qué mejor órgano para garantizar la tranquilidad y el orden público que el propio jefe superior político! Se podía estimar de mayor peligrosidad dar un paso tal con la creación de esta Junta, en vez de permanecer mientras tanto bajo las autoridades establecidas hasta el momento.

Lo que queremos decir es que la Junta evidentemente rompía el orden legal consagrado. Nosotros pensamos que existe algo más en el trasfondo: al menos históricamente, dicha Junta marca el inicio del proceso de la autodeterminación soberana y libre del Estado de Yucatán.

Así fue. Pues aparte la motivación política de diversa índole que se alega en el Manifiesto, se dice expresamente que la creación de tal Junta encuentra su fundamento último en la base número 10 de las del Plan de Casa Mata, al autorizarse una Junta Administrativa para Veracruz. Decía el Manifiesto:

«En consecuencia, la Ecma. Diputación Provisional, sin embargo de encargársele por el artículo 10 del Plan de Casa Mata, el poder administrativo...» ${ }^{23}$

Aunque resulte un tanto caprichosa la asimilación, véase el nexo real entre los postulados de dicho Plan y la acción para comenzar a caminar por unos senderos novedosos y distintos a los previstos hasta entonces. Nótese también, cómo es la Diputación y no otro órgano o autoridad, la que toma la iniciativa, dirigiéndose a los ayuntamientos, para merecer la aprobación de dichas corporaciones.

La diputación, que se considera con la suficiente autoridad y el suficiente poder moral para introducir tamañas novedades, sin duda poseía la autoridad y el poder bastante para mantener ese mismo orden y tranquilidad siguiendo lo establecido hasta entonces. Evidentemente, estamos asistiendo a un movimiento de profundo significado. Por eso, es necesario hacer la consulta a los diversos ayuntamientos, tal como lo harán otras diputaciones, como la propia de Jalisco.

El Manifiesto es obra de una comisión especial, por acuerdo de la Diputación, firmado por Pedro Almeyda, Pablo Moreno, Manuel Carvajal, Manuel García Sosa y Juan de Dios Cosgalla.

Al parecer, la diputación entregó un pliego con cuatro proposiciones para su estudio, relativas, unas a la formación de una Junta provisional administrativa; otras veían la posibilidad de nombrar a dos comisionados que deben situarse a la

${ }^{23}$ Ibidem. 
inmediación del ejército libertador; otras más, trataban el asunto de la posibilidad de hacer una nueva convocatoria para reunir a un nuevo constituyente; ordenando que todas las decisiones que se tomaran, se pusieran en conocimiento de una Junta que estaba trabajando en Puebla, cerca del cuartel general de los levantados contra Iturbide. $^{24}$

Según esto, se confirma la existencia de la reunión en Puebla, es decir, se confirma que era general y universal el movimiento de adhesión contra el Emperador; y se demuestra la concatenación de unos y otros acontecimientos. Por lo visto, en Puebla se acordó el día 2 de marzo tener una nueva reunión para nombrar diputados a Cortes, la cual muy posiblemente tuvo lugar el 9 del mismo mes, ${ }^{25}$ a tan sólo dos días de haberse reinstalado el Congreso, disuelto por Iturbide.

En consecuencia, la diputación adoptada el mismo día 9 de abril el Plan que propone la comisión, nombrada por la Excma. Diputación Provincial, para la formación de dicha Junta Provisional Administrativa. Este Plan consta de 14 puntos, en los cuales se describe fundamentalmente el procedimiento que ha de seguirse para la elección de los posibles vocales (artículo 1) de entre 23 electores, correspondientes a los 15 partidos de la provincia, quienes el día 18 de mayo tenían que reunirse en la capital para designar a cinco individuos de que constaría la Junta (artículo 8) y cinco suplentes (artículo 11).

El artículo 13 del Plan facultaba a la Diputación para formar el proyecto de reglamento de la Junta Provisional Administrativa, el cual proyecto se pasaría a los electores para que pudieran adicionarlo o desecharlo, en todo aquello que no crean ser conforme a razón, derecho y justicia.

Mientras que el 14 preveía que, sin embargo de que debe expresarse que dentro de poco tiempo cesarán las causas que han inspirado la necesidad de esta Junta, si sucediere que dure, deberán renovarse sus individuos anualmente de tres en tres. ${ }^{26}$

Las cosas no pararon aquí. De hecho, se resolvió obligar al Congreso reinstalado, para que fuera quien elaborara la nueva convocatoria. Sin embargo, la resistencia del Congreso para hacer la nueva convocatoria, trajo como resultado la toma de medidas aún más extremas, como las de obstruir y no obedecer las disposiciones del gobierno central, hasta llegar a la declaración llana de la autodeterminación libre y soberana.

En efecto, estas medidas se encuentran en el Acta de la Junta General de las Corporaciones, Gefes y Electores de Partido, quienes tuvieron a bien rubricar en

\footnotetext{
${ }^{24}$ Ibidem.

25 Ibidem.

${ }^{26}$ En Águila Mexicana del día 16 de mayo de 1823.

${ }^{27}$ Véase el documento en Águila del 21 de junio de 1823.
} 
todo las medidas adoptadas de autodeterminación y el propósito de erigirse en Estado libre y soberano. ${ }^{27}$ Sobre este particular, se decía:

«... fundados en las más enérgicas y poderosas razones, se constituya desde este mismo día en República Federada esta provincia bajo las bases siguientes: que Yucatán jura, reconoce y obedece al Gobierno Supremo de México siempre que sea liberal y representativo, pero con las condiciones que siguen: que la unión de Yucatán será la de una República federada y no en otra forma, y por consiguiente tendrá derecho a formar su constitución particular y establecer las leyes que juzgue convenientes a su felicidad.»

Se resolvió también, entre otros puntos, la creación de una junta Provisional Gubernativa y que dicha Junta se acomode al decreto de las Cortes de España de 8 de abril de 1813; y la convocatoria para la formación de un Senado provincial sin distinción de clases.

Acto seguido, se procedió a la instalación de dicha Junta, la cual quedó conformada por los ciudadanos Tiburcio López y Francisco Facio, entre otros, según las noticias que recoge Águila Mexicana. En todo caso, decía el texto de su juramento:

¿Juráis a Dios sostener el sistema adoptado de República federada en la provincia, sin permitir en ella otra clase de gobierno y cumplir con todas las obligaciones de vuestro encargo?

Este documento lleva la fecha de 30 de mayo de 1823.

D) En el caso de Zacatecas.

En Zacatecas, un decreto de 23 de octubre de 1823 ordenaba:

Se observarán y se harán observar con exactitud en todo el Estado las leyes comunes constitucionales de España y particulares de la Nación, que estaban vigentes al tiempo de declararse esta provincia en Estado libre y federado, y posteriores, en lo que no pugnen con el referido sistema. ${ }^{28}$

E) En el caso de Veracruz.

La secuencia es la misma, primero se confirma a las autoridades para que continúen laborando como hasta ahora, conforme a las leyes en vigor y, a continua-

${ }^{28}$ Este caso también ha sido estudiado en nuestro libro ya citado, Introducción al Federalismo.

${ }^{29}$ Véase su Colección de leyes, decretos y órdenes, expedida en Xalapa, a partir de 1825. La cita en Tomo I, p. 17. 
ción, inclusive se procede a la transformación de alguna de las instituciones tradicionales en una nueva, como es el caso del jefe superior político, Miguel Barragán, quien pasa a ser el primer Gobernador provisional del nuevo Estado libre y soberano de Veracruz. Veamos: en el primer decreto del Constituyente de 9 de mayo de 1824 , en su número $4^{\circ}$ y $5^{\circ}$ dispuso:

$4^{\circ}$ Residirá el poder ejecutivo en una persona con denominación de Gobernador del Estado: entre tanto se nombra éste, desempeñará sus funciones el jefe político. ${ }^{29}$

$5^{\circ}$ Las autoridades que boy ejercen el poder judicial, continuarán ejerciéndolo.

Por otro lado, mediante el decreto número 5 del día 11 de mayo se confirma a las demás autoridades en los términos siguientes:

«Número 5. El Congreso del Estado libre de Veracruz, decreta: los ayuntamientos y demás corporaciones civiles continuarán funcionando como hasta aquí con sujeción a las leyes vigentes.» ${ }^{30}$

F) En el caso del Estado de México

Veamos el caso del Estado de México. En los primeros decretos, expedidos por el Congreso Constituyente, se procede a confirmar al Jefe Superior Político, que es el general Múzquiz, para que continúe ejerciendo su cargo, pero ahora con el nombre de gobernador provisional del Estado. ${ }^{31}$

Después, se emite otro decreto y en su artículo 8 se afirma que el nuevo Poder Judicial del Estado residirá por ahora en las autoridades que actualmente lo ejercen, que es la Audiencia, como se precisa en el artículo 9, haciendo uso de las facultades que hasta hoy tiene. Mientras que el artículo 10 confirma a las demás autoridades civiles, eclesiásticas y militares, para que sigan desempeñando sus cargos, arreglándose en todo a las leyes vigentes. ${ }^{32}$

\section{G) En el caso de Guanajuato}

Iguales previsiones se encuentran para el Estado de Guanajuato en los artículos 2 y 4 del decreto del día 25 de marzo del año de 1825, el cual puede consultarse en la Colección de decretos del Congreso constituyente y del primero constitucional

${ }^{30}$ Véase en la misma obra. Tomo I. p. 19.

${ }^{31}$ Se trata del primer decreto del día 2 de marzo de 1824 . Véase en Colección de decretos y órdenes del Estado de México, Toluca, 1848. Tomo I, página 5 y 6.

${ }^{32}$ Véase el texto de este otro decreto en la misma Colección, Tomo I, página 5. 
del Estado de Guanajuato, publicado por la imprenta del periódico Aguila Mexicana, México 1834.

\section{H) En el caso de Michoacán}

El caso del Estado de Michoacán. En la Colección de Corominas encontramos el decreto del día 6 de abril de 1824, el cual en el artículo 12 trae las previsiones relativas a la confirmación de las autoridades para que continúen ejerciendo sus funciones con apego a las leyes vigentes.

I) En el caso de las provincias internas de occidente

Son cuatro las llamadas provincias internas de occidente, Nueva Vizcaya, Sonora, Sinaloa y Nuevo México. Al principio se propusieron formar un solo departamento bajo el nombre de Estado Interno occidental de la Federación Mexicana.

Pues bien, en relación con nuestro tema, leemos en el artículo 6 y16 de un Acta firmada en Durango el día 30 de junio de 1823, lo siguiente:

8. Las autoridades constituidas, empleados actualmente en el Estado de cualquier clase, y dignidad que sea, subsistirán sin novedad, y no serán removidos sino con arreglo a las leyes, y a juicio del mismo Estado.

16. En todo caso, y mientras no se forma la constitución general y códigos legales del Estado, regirá la española, y quedarán vigentes los que hoy gobiernan en cuanto no se opongan al sistema que de presente se adopta.

\subsection{Sobre los cuerpos de leyes declarados en vigor}

Ahí está el tipo de declaraciones que, para considerar en vigor en México una ley emitida por las autoridades españolas, debían haberse producido por parte de las mismas autoridades mexicanas.

Unas declaraciones, como hemos visto, fueron emitidas por las autoridades generales, para toda aquella geografía que inicialmente quiso constituirse bajo la idea de un Imperio, desde Nuevo México hasta la frontera con Panamá al sur; otras declaraciones fueron ya hechas para el interior de cada una de las provincias y, en su caso, Estados.

¿Cuáles eran entonces los cuerpos de leyes que fueron declarados como vigentes? 
La respuesta es muy sencilla, pues basta con acudir a las colecciones de leyes que, por órdenes de las mismas autoridades mexicanas, se ordenaron formar para facilitar su consulta y su aplicación. Y en ellas, desde luego, se insertan las leyes españolas que, como hemos venido viendo, se declararon vigentes.

Hay varias colecciones. Nosotros ahora nada más vamos a mencionar tres: las Pandectas de Rodríguez de San Miguel; la famosa colección de Dublán y Lozano y la de Galván, que solamente se refiere a las leyes expedidas por las Cortes españolas de Cádiz.

\section{A) Las Pandectas Hispano-mexicanas.}

Las Pandectas Hispano-mexicanas, es una obra clásica del Derecho mexicano del siglo XIX, de don Juan N. Rodríguez de San Miguel. Fue publicada en 1839 y en el año de1852. Ahora, o más recientemente ha sido reimpresa por nuestra compañera María del Refugio González en 1980 y 1991.

¿Qué son las Pandectas Hispano-mexicanas?

Para los propósitos de este trabajo, son lo que indica el subtitulado de la misma obra, que transcribimos:

«O sea Código General comprensivo de las leyes generales, útiles y vivas de las Siete Partidas, Recopilación Novísima, la de Indias, autos y providencias conocidas por de Montemayor y Beleña y cédulas posteriores hasta el año de 1820, con exclusión de las totalmente inútiles, de las repetidas; y de las expresamente derogadas.» ${ }^{33}$

No existe mejor testimonio sobre la recepción de las leyes españolas, castellanas y de Indias, en el México independiente, que esta obra de uno de los juristas más famosos del siglo XIX mexicano.

Rodríguez de San Miguel nace en Puebla en 1808 y muere en 1877. La edición de 1980 y la de 1991 es una reproducción de la edición de 1852.

Nuestra compañera, María del Refugio González, en su estudio introductorio, preparado para la edición de las Pandectas Hispano-mexicanas, de Juan N. Rodríguez de San Miguel, de 1991, apoyándose en Alfonso García-Gallo, comenta:

«Siguiendo a este autor, se puede afirmar que el orden jurídico indiano y, por supuesto, el novohispano, formaban parte del sistema jurídico castellano, aunque para las Indias, el Derecho de Castilla era común o general, y el indiano el particular o especial.» ${ }^{34}$

${ }^{33}$ Como decimos, el texto transcrito pertenece al título de la obra, por tanto, viene en la portada de la misma. El propio autor, en la parte introductoria, explica el sentido de la recopilación y el orden seguido.

${ }^{34}$ La cita se encuentra en la página XVIII, 
De conformidad con lo expuesto, la autora citada, dice que este Derecho estaba conformado, primero: por las Partidas, Fuero Real, Fuero Juzgo, Ordenamiento de Alcalá, Nueva Recopilación de 1567 y Novísima Recopilación de 1805;35 más las fuentes del Derecho Canónico, como el llamado Decreto de Graciano, etcétera.

A continuación, la autora va pasando revista completa de cada una de las fuentes del Derecho Novohispano, en donde entran, las compilaciones, como la de Puga de 1563; la recopilación general de las Leyes de Indias; las leyes dictadas por facultades delegadas, etcétera. Se trata de una inmensa labor legislativa, como todos sabemos.

B) En la Legislación mexicana de Dublán y Lozano.

Sin lugar a dudas, estamos ante la colección más importante de todas, por su alcance y por su contenido, preparada por dos grandes constitucionalistas, como son don José María Lozano y don Manuel Dublán.

La obra de José María Lozano y Manuel Dublán inició su publicación en 1876. Se trata de una compilación oficial, como lo hemos dicho, ordenada por el gobierno para incorporar, junto a las leyes mexicanas, expedidas a partir de la Independencia de 1821, las reales cédulas no recopiladas y un número importante de decretos y de órdenes aprobadas por las Cortes españolas de Cádiz.

Se trata de una colección que fue recogiendo en sus páginas las leyes sueltas, no las codificadas, tanto de autoridades españolas como de autoridades mexicanas.

Leyes codificadas evidentemente son las recogidas por Rodríguez de San Miguel y todos sabían que estaban en vigor; que eran de fácil acceso y que eran aplicables. El interés oficial de recoger las leyes sueltas, o las leyes no recopiladas, como indican sus autores, no era otro sino el de facilitar su conocimiento y para su mejor aplicación.

Pues bien, entre estas leyes sueltas, se encuentra una lista muy larga de decretos y órdenes expedidos por las Cortes españolas de Cádiz, tal como lo indican los mismos autores en la primera página de Advertencia: al decirnos cuáles son las leyes que se incorporan a su colección:

I. Las reales cédulas no recopiladas que, en todo o en parte, se consideran vigentes en la República.

II. Los decretos de las Cortes Españolas en sus épocas, que puedan ser obligatorios para México.

${ }^{35}$ La cita se encuentra en la p. XVIII. 

dad. $^{36}$

III. Los expedidos durante el reinado de Fernando VII, que tengan la misma cali-

De manera que, hablando de las leyes expedidas por las Cortes de Cádiz, hace el siguiente comentario:

Muchas de las leyes de esta asamblea (Cortes Españolas de Cádiz) han servido de base a la legislación patria; y algunas aún después de tantos años, por falta de ley mexicana, tienen frecuente aplicación en nuestros tribunales.

Volvemos a repetir el año en que se inicia la Colección de Dublán y Lozano, es el año de 1876. ¿Qué se podía decir acerca de la vigencia de esta misma clase de leyes de las Cortes de Cádiz a la temprana fecha de 1828, que es la fecha de aparición de la tercera colección que hemos ofrecido mencionar?

C) La colección de Galván de 1828.

He aquí el título completo de esta obra: Colección de los decretos y órdenes de las Cortes españolas, que se reputan vigentes en la República de los Estados Unidos Mexicanos Como ya lo hemos dicho fue publicada por la imprenta de Galván en 1828 y reimpresa recientemente por la Suprema Corte de Justicia de la Nación de manera facsimilar, en el año del 2006.

¿Y qué clase de leyes son las que aquí se recogen provenientes de las Cortes de Cádiz?

Esta colección contiene unas 181 disposiciones, salvo error al ser contadas por su servidor, entre decretos y órdenes sobre materias muy diferentes.

Desde nuestro punto de vista, por un lado, podemos mencionar todas aquellas que consagran derechos y libertades, gracias a las cuales se crea un régimen de total liberalización de la economía y de la vida social, subsanando el error, cometido por aquellas Cortes, de no haber abolido la esclavitud, ni haber reconocido el derecho de ciudadanía a todos sus habitantes, errores, insistimos, subsanados desde el inicio del movimiento insurgentes de 1810 en Guadalajara; e igualmente subsanado en cada una de las constituciones locales de este primer periodo.

Y, por otro lado, debemos mencionar también todas aquellas otras disposiciones que se dictaron para la organización de los ayuntamientos; para la impartición de justicia; así como para consolidar oras varias instituciones de origen gaditano, como vamos a ir ejemplificándolo a continuación.

\footnotetext{
${ }^{36}$ Esta advertencia se encuentra en el Tomo I, p. 3 y 4.
} 


\section{SU CONSOLIDACIÓN EN LAS INSTITUCIONES LOCALES}

Su servidor ha partido de la idea preliminar de la vigencia de una serie importante de decretos y de órdenes emanadas de aquellas Cortes, entre los que debe sobresalir, la misma Constitución del 19 de marzo de 1812, por el solo hecho de haber seguido la Nueva España vinculada a las autoridades peninsulares, al sofocarse, primero, el movimiento juntero de 1808; y luego el mismo movimiento insurgente hacia 1814.

En páginas atrás, hemos hecho la referencia a esta vigencia obligatoria de la Constitución de Cádiz en la Nueva España, ya que tenemos constancias bastantes de haber sido jurada en tales periodos.

Por otro lado, también hemos hecho la referencia a las diferentes e importantes declaraciones de vigencia que de la misma Constitución de 1812 y de otras muchas leyes españolas hicieron las propias autoridades mexicanas durante el proceso largo de reafirmación de la Independencia de España y del proceso de consolidación de nuestra propia organización política.

Falta todavía mostrarle al lector la forma en que, por haberse incorporado a la organización propia de cada Estado y, en algunos supuestos, hacia el interior de la misma entidad federativa mexicana, muchas de las instituciones gaditanas fueron consolidadas definitivamente en México después de su independencia. Esto es lo que vamos a tratar de presentarle al lector a continuación.

\subsection{El punto de partida}

Cuando se consuma la victoria militar sobre don Agustín de Iturbide y se le obliga a salir exiliado, toda aquella geografía política, que intentó organizarse bajo la idea de Imperio, desde Nuevo México al norte hasta llegar a la frontera con Panamá al sur, aparecía organizada según las previsiones de la Constitución de Cádiz. Esto es, dicho territorio estaba dividido en provincias y éstas en municipios. En cada provincia existe una Audiencia territorial y unos juzgados, regulados por la misma Constitución de Cádiz.

Y, desde luego, las autoridades competentes (de conformidad con las disposiciones, que ya hemos visto del Plan de Iguala y Tratados de Córdoba de 1821; de la Soberana Junta Provisional Gubernativa de 1821 y del primer Congreso Constituyente Mexicano de 1822) habían declarado expresamente la vigencia de dicha Constitución; y habían rehabilitado a todas las autoridades, civiles, eclesiásticas y militares, para que continuasen ejerciendo sus funciones como hasta la fecha y con apego a la legislación vigente hasta entonces.

Así pues, en este contexto de las normas gaditanas vigentes, de la misma vi- 
gencia de las instituciones gaditanas de la provincia y los municipios, cuando se inicia el movimiento de autodeterminación de dichas provincias; las de Centro América, buscando formar entre ellas una federación; mientras que las provincias mexicanas, unas querían mantenerse unidas, como queriendo formar un país de manera unitaria; y otras resueltamente se autodeterminaron dejando abierta la posibilidad de llegar a formar una federación, lo cual se consiguió con la firma del Acta constitutiva del 31 de enero de 1824.

Bien, el punto de partida entonces de nuestro estudio no es otro sino esos hechos reales que nos están sirviendo de referencia.

En ese momento histórico, que va desde la entrada en escena de don Agustín de Iturbide con su Plan de Iguala y hasta su salida de México rumbo a Londres, todos los pueblos están organizados bajo esa forma de división en provincias y éstas en municipios, según las previsiones de la Constitución de Cádiz.

Y ya vimos en páginas atrás cómo esas mismas autoridades de origen gaditano, no sólo impulsan el movimiento de autodeterminación, sino que, al hacerlo, se apoyan en la misma legislación gaditana; y, lo que es mucho más importante, cada nuevo Estado en que se autodeterminarán, incorporará a su propio texto particular constitucional lo mejor de esa misma legislación gaditana.

Esto es lo que nos permite hablar a nosotros de una verdadera consolidación de las instituciones de origen gaditano, algo así como si aquellas Cortes hubieran trabajado nada más, o principalmente, para la Nueva España, de manera tal que esta organización gaditana de provincias y municipios luego emprenden el camino hacia su autodeterminación y, en su caso, su integración en el Estado federal mexicano, conservando siempre lo mejor de dicha legislación.

\subsection{Las 19 constituciones de referencia}

Empiezan a promulgarse después de firmada la propia Constitución de los Estados Unidos Mexicanos, que data del día 4 de octubre de 1824, ya que estaba prohibido que fueran publicadas antes de dicho texto federal.

Nosotros estamos siguiendo su consulta en la edición hecha en la imprenta de Galván a cargo de Mariano Arévalo, en tres tomos, México 1828, reimpresa últimamente en el año 2005 por Miguel Angel Porrúa y la H. Cámara de Diputados.

He aquí la secuencia de su publicación por parte del respectivo congreso constituyente:

La de Jalisco, que es del 18 de noviembre de 1824.

La de Oaxaca, del 10 de enero de 1825. 
La de Zacatecas, del 17 de enero de 1825.

La de Tabasco, de 15 de febrero de 1825.

La de Nuevo León, del 5 de marzo de 1825.

La de Yucatán, del 6 de abril de 1825.

La de Tamaulipas, del 6 de mayo de 1825 .

La de Veracruz, del 3 de junio de 1825.

La de Michoacán, del 19 de julio de 1825.

La de Querétaro, del 12 de agosto de 1825.

La del Estado libre de Occidente, del 31 de octubre de 18

La de Chiapas, del 25 de noviembre de 1825.

La de Chihuahua, del 7 de diciembre de 1825.

La de Puebla, del 10 de diciembre de 1825

La de Guanajuato, del 14 de abril de 1826.

La de Durando, del 1 de septiembre de 1826.

La de San Luís Potosí, del 16 de octubre de 1826.

La del Estado de México, del 14 de febrero de 1827.

La de Coahuila y Tejas, del 11 de marzo de 1827.

\subsection{Siguiendo el modelo de la Constitución gaditana}

Si observamos con atención cada una de estas 18 constituciones, excluyendo la de Veracruz, veremos que siguen muy de cerca el formato, externo e interno, de la Constitución de Cádiz. No es que la estén copiando al pie de la letra, sino que la están tomando como modelo, haciendo propias las cosas que les parece en cada caso, que deben mantenerse.

\section{A) El principio de la soberanía}

Entre los principios, que se mantienen, tenemos el de la soberanía nacional, el cual se enuncia en términos iguales y parecidos al enunciado del artículo 3 de la Constitución Española; o iguales y parecidos los enunciados que encontramos en las primeras constituciones locales de lo que era el Reino de la Nueva Granada, que son anteriores al enunciado de la constitución gaditana. Veamos algunos ejemplos.

a) En la de Oaxaca

Art. 2. La soberanía de este Estado reside originaria y exclusivamente en los individuos que la componen: por tanto, a ellos pertenece exclusivamente el derecho de formar, por 
medio de sus representantes, su constitución política; y el de acordar y establecer con arreglo a ella, las leyes que sean conducentes a su conservación, seguridad y prosperidad interior. ${ }^{37}$

b) En la de Tabasco

Art. 2. El Estado retiene su libertad, y su soberanía reside esencialmente en los individuos que le componen: por tanto pertenece a ellos exclusivamente el derecho de formar por medio de sus representantes su constitución, y el de acordar y establecer con arreglo a ella las leyes que requiera su conservación, régimen, seguridad y prosperidad interior.

c) En la de Yucatán

Art.2. El Estado yucateco es soberano, libre e independiente de cualquiera otro.

Art. 3 La soberanía del Estado reside esencialmente en los individuos que le componen, y por tanto a ellos pertenece exclusivamente el derecho de formar, reformar y variar por medio de sus representantes su constitución particular, y el de acordar y establecer con arreglo a ella las leyes que particularmente requiera, su conservación, régimen, seguridad y prosperidad interior.

d) En la Acta constitutiva de la federación

Este enunciado viene en su artículo 3, el cual dice:

Art. 3.La soberanía reside radical y esencialmente en la nación, por lo mismo pertenece exclusivamente a ésta el derecho de adoptar y establecer por medio de sus representantes la forma de su gobierno y las demás leyes fundamentales que le parezca más conveniente para su conservación y mayor prosperidad, modificándolas o variándolas, según crea convenirle más. ${ }^{38}$

Es verdad que algunas de estas 19 constituciones no contienen un enunciado como los citados, sino que solamente se limitan a decir que el Estado, por ejemplo el de Jalisco, retiene su libertad y soberanía en todo lo que toque a su administración y gobierno interior, en palabras del artículo 2.

Esto es así, porque, de hecho, en documentos anteriores ya se había explicado ampliamente el significado de la soberanía que Jalisco estaba reclamando y defendió, junto con Zacatecas, por vía de las armas, tal como lo explicamos nosotros en nuestro libro Introducción al federalismo: la formación de poderes 1824, editado por la Universidad Nacional Autónoma de México, México 1978.

Sobra advertirle al lector que en la redacción de este enunciado fue determi-

${ }^{37}$ La constitución del Estado de Oaxaca se encuentra a partir de la p.162 del tomo II de la obra Colección de Constituciones de los Estados Unidos Mexicanos, ya citada. Y el texto de los artículos 1 y 2 , en la p.165.

${ }^{38}$ El texto de esta Acta constitutiva, firmada el 31 de enero de 1824 se encuentra en la misma Colección, que venimos citando, en el tomo I. La cita véase en la página 2. 
nante la participación de don Miguel Guridi y Alcocer, quien ahora consiguió que se pusieran los dos adverbios de radical y esencialmente, comentando que así era como él lo había propuesto cuando se discutió el artículo 3 de la constitución de Cádiz. También aclaró que por nación, debía entenderse el conjunto de los habitantes asentados en el territorio.

e) El caso de Tunja, ejemplo comparativo

Tenemos a la mano una copia del texto original de su constitución, publicado en Santa Fe de Bogotá en la imprenta de don Bruno Espinosa, en el año de 1811, sancionado en plena Asamblea de los representantes de toda la Provincia, en sesiones continuas desde el 21 de noviembre hasta el 9 de diciembre de 1811, según se dice en la misma portada.

Comienza con una especie de preámbulo solemne, en donde se expresa la encomienda que han recibido de parte del pueblo o de sus comitentes, la cual tiene por finalidad la de deliberar sobre la forma de gobierno que se debe abrazar uniformemente en ella, y fijar las bases de una Constitución que consecuentemente garantice los derechos del hombre en sociedad.

Por tanto, han convenido de manera espontánea y unánimemente en bacer las declaratorias y fijar las bases de gobierno siguientes...

$\mathrm{Y}$ es en esta parte, que habla de los derechos del hombre en sociedad, en donde vienen los enunciados formales de la soberanía, como si para ellos las prerrogativas de la soberanía fueran exactamente derechos naturales del hombre en sociedad:

18. La soberanía reside originaria y esencialmente en el pueblo; es una, indivisible, imprescriptible e inenajenable.

19. La universalidad de los ciudadanos constituye el Pueblo Soberano.

20. La soberanía consiste en dictar leyes, en la de hacerlas ejecutar y aplicarlas en los casos particulares que ocurran a los ciudadanos, o en los poderes Legislativo, Ejecutivo y Judicial.

El tema de la soberanía puede estudiarse en uno de los capítulos de nuestro libro Temas del liberalismo gaditano, editado por la Universidad Nacional Autónoma de México, México, 1978.

B) El principio en materia de religión

Los enunciados son iguales lo mismo en las constituciones locales del Nuevo 
Reino de Granada que en la Constitución española de Cádiz de 1812 y las mexicanas de esta etapa de 1824-1827.

Por decirlo con un ejemplo, he aquí el enunciado del Acta Constitutiva de la federación mexicana del 31 de enero de 1824:

Art.4. La religión de la nación mexicana es y será perpetuamente la católica apostólica romana. La nación la protege por leyes sabias y justas, y probíbe el ejercicio de cualquier otra.

C) El principio de la división de poderes

No obstante que la Constitución de Cádiz estuvo hecha para una monarquía, el enunciado relativo al principio de la división de poderes es igual al que contienen cada una de las 19 constituciones mexicanas, las cuales declaran que su respectiva forma de gobierno es la republicana, representativa, popular y federal. He aquí lo que dice la Constitución de Oaxaca: deral.

Art. 31. El gobierno del Estado de Oaxaca es popular, representativo, republicano fe-

Art.33. El ejercicio del supremo poder del Estado se conservará dividido en legislativo, ejecutivo y judicial y nunca podrán reunirse estos tres poderes ni dos de ellos en una sola persona o corporación. ${ }^{39}$

Mientras que en Yucatán se enuncia el mismo principio de la siguiente manera: deral.

Art. 13. El gobierno del Estado de Yucatán es republicano, popular, representativo fe-

Art. 15. El ejercicio del poder supremo del Estado se conservará dividido, para jamás reunirse, en legislativo, ejecutivo y judicial. ${ }^{40}$

D) El principio de la igualdad y la abolición de la esclavitud

He aquí una enmienda muy importante que las constituciones locales neogranadinas y mexicanas le hacen a la de Cádiz: la de declarar abolida la esclavi-

${ }^{39}$ El texto del artículo 31 se encuentra en la p.177 y el texto del artículo 33, en la página.178 del mismo tomo II, de la obra ya citada.

${ }^{40}$ La constitución del Estado de Yucatán puede consultarse a partir de la p.328 del tomo III, de la Colección de Constituciones de los Estados Unidos Mexicanos, ya citada. El texto de los artículos ahora mencionados se encuentra en la página. 330, 331 y 336. 
tud, reconociendo por tanto el principio de la igualdad natural entre todos los seres humanos y el reconocimiento del principio de la ciudadanía a favor de quienes de sus habitantes reúnan los requisitos de edad, vecindad, etcétera.

En el Estado de Michoacán quedó abolida la esclavitud mediante el siguiente enunciado:

Art. 14 En consecuencia queda para siempre abolido en el territorio del Estado el comercio y tráfico de esclavos; y los que en él existen actualmente se darán por libres con la indemnización correspondiente, si lo exigieren los dueños. ${ }^{41}$

E) El municipio, base de la división territorial de cada Estado

Hablamos del municipio regulado por la Constitución de Cádiz, que es el que existe a la hora en que cada Provincia se transformó en Estado. En todos los Estados, no obstante que hacia su interior hagan una división territorial en departamentos, por ejemplo, o en cantones, o en partidos, en todos los supuestos la base de la organización territorial es el municipio con su ayuntamiento, electo popularmente.

Pero no sólo es la base de su división territorial, sino que, tomando en cuenta la forma en que es concebido por las Cortes de Cádiz, así como tomando en cuenta las importantes funciones que se le encomiendan, también es el motor del desarrollo y del progreso de todo el Estado.

Como se recordará, el artículo 310 de la Constitución de Cádiz estableció que debía haber ayuntamientos en los pueblos que lleguen a tener, por sí o por su comarca, mil almas.

Por ello es que, hablando de la formación de los ayuntamientos constitucionales, el decreto del 23 de mayo de 1812 estableció en su artículo primero vuelve a insistir en esta idea, diciendo que se tomen en cuenta sus particulares circunstancias de agricultura, industria o población, para que el gobierno pueda proveer lo conveniente. ${ }^{42}$

Recomendamos igualmente la lectura del decreto de 23 de junio de 1813 conocido como Instrucción para el gobierno económico político de las provincias, para conocer las encomiendas que se le hacen al ayuntamiento y valorar la importancia que se le atribuye. Este decreto se encuentra en la misma Colección de Galván a partir de la página 85 .

Como quiera que sea, estos ayuntamientos gaditanos siguen siendo la base de la división política y territorial de los Estados en México.

\footnotetext{
41 Véase este texto en el mismo libro que venimos citando, tomo II. Página 7.

${ }^{42}$ Este decreto se incorporó a la Colección de Galván por considerar que estaba en vigor y se encuentra en la página 28 y siguientes.
} 
F) Sobre el sistema de elecciones indirectas

En todas estas primeras constituciones, con la sola excepción de la constitución del Estado de Veracruz, viene una muy amplia y detallada regulación de las elecciones, siguiendo siempre el modelo gaditano.

La constitución de Veracruz es muy breve y por ese motivo no vienen los detalles del régimen electoral, pero en todo caso, se aplica el mismo sistema aprobado por las Cortes españolas de Cádiz, cuya Constitución fue declarada como vigente en dicho Estado de Veracruz.

Veamos, para ejemplificarlo, como era regulado en la constitución de Oaxaca.

La Constitución del Estado de Oaxaca divide su articulado en 28 capítulos. La regulación del proceso electoral para elegir a los integrantes tanto de su Cámara de Diputados como a los de su Senado viene en el capítulo VI, consagrado a regular las Juntas de parroquia; en el capítulo VII, dedicado a regular las Juntas departamentales; y en el capítulo VIII, que regula la Junta electoral del Estado. ${ }^{43}$

a) De las juntas de parroquia

Se compondrán de todos los ciudadanos que estén en el ejercicio de sus derechos avecindados y residentes en el territorio, en palabras del artículo $38 .{ }^{44}$

Deberán celebrarse cada dos años precisamente el día 15 del mes de agosto, previa convocatoria que con anterioridad de ocho días expedirá la autoridad local, es decir, el alcalde o quien haga sus veces. Tiene carácter público.

La base de esta elección será la población de manera que se elegirá un elector por cada mil almas; si la población llegase a mil quinientas se elegirán dos electores; si a dos mil quinientas, tres electores y así progresivamente, dice el artículo 39. Pero si la población nada más llegase a quinientas almas, de todas maneras se elegirá un elector. Para los supuestos en que la población fuere menor de quinientas, dicha población se sumará con la población más cercana.

Bien, reunidos el día señalado y en el lugar indicado, la junta parroquial será presidida por la primera autoridad del lugar en donde haya sido convocada. Y una vez que se hubieren reunido cuando menos treinta personas, se procederá al nombramiento de cuatro escrutadores y un secretario. Ahora bien, si para las doce horas del día de la reunión, no hubieran concurrido dichas treinta personas, de todas formas se nombrarán a los escrutadores y al secretario de entre los presentes.

${ }^{43}$ Véase en Colección de Constituciones de los Estados Unidos Mexicanos, ya citada, t. II. p. 179 y siguientes.

${ }^{44}$ Ibidem. p. 179. 
Hechos estos nombramientos, en seguida el presidente dirá en voz alta: se procede al nombramiento de los electores parroquiales, en palabras del artículo 41. A continuación, los ciudadanos irán pasando de uno en uno a la mesa y ante el secretario, de viva voz darán el nombre de la persona que decidan elegir. El secretario anotará dicho nombre en un registro que llevará al efecto.

Es ahora cuando se les encomienda al presidente de la mesa, así como a los escrutadores y al secretario las siguientes facultades de carácter jurisdiccional, que tienen que ver con la salva guarda de los requisitos tanto para votar como para poder ser votado. Dice el artículo 42:

Art. 42. El presidente, los escrutadores y secretario decidirán en el acto y sin ningún recurso para aquella sola vez y para aquel solo efecto las tachas que se pongan en la junta a votantes y votados, dejando a salvo su respectivo derecho. ${ }^{45}$

Para estos efectos, el artículo 21 señala los requisitos que deben reunir las personas que para obtener la calidad de ciudadano oaxaqueño, así como el procedimiento solemne por medio del cual se obtiene la patente de ciudadano, dice el artículo $25 .^{46}$

El artículo 26 reconoce el derecho a su favor el poder votar para la elección de los electores parroquiales, así como el derecho genérico para ocupar cargos públicos en el Estado, cumpliendo los requisitos que, para cada caso, se establezcan. ${ }^{47}$

Luego, por su parte, el artículo 27 establece las causas por las cuales se puede llegar a perder la calidad de ciudadano. Mientras que el artículo 28, indica las causas de suspensión de dicha prerrogativa. ${ }^{48}$

Y, al lado de estos requisitos y demás causales de pérdida y de suspensión de la patente de ciudadano, por así decirlo, se precisa los ilícitos penales de carácter electoral, como ahora decimos, o los ilícitos que pueden darse durante este proceso de elecciones parroquiales. Dice el artículo 43.

Art. 43. Por el cobecho, el soborno y la calumnia se pierde el derecho de voz activa y pasiva en todas las elecciones, en las cuales nadie podrá votase a sí mismo. ${ }^{49}$

A continuación, el artículo 44, después de volver a decir que las elecciones se harán a puerta abierta y sin guardias prohíbe de manera categórica el acudir a este proceso portando armas, de cualquier clase que sean. ${ }^{50}$

La lista de los delitos electorales es más amplia. Aquí, como vemos, se están actualizando los que tienen que ver con la jornada electoral, por así decirlo.

\footnotetext{
${ }^{45}$ Ibidem. p. 180 y 181.

${ }^{46}$ Ibidem. p. 174.

${ }^{47}$ Ibidem. p. 175.

${ }^{48}$ Ibidem. p. 175 y 176.

${ }^{49}$ Ibidem. p. 181.

${ }^{50}$ Ibidem. p. 182.
} 
La jornada de votaciones dura dos días, la Constitución del Estado de Oaxaca regula las solemnidades con que se publicitan los resultados de la votación y se extienden las actas correspondientes, incluida la certificación que deberá acreditar al ganador o a los ganadores en dicho proceso.

b) Las juntas departamentales y su competencia

Nueve artículos, bajo el rubro del capítulo VII, regulan la organización y el funcionamiento de las juntas electorales de departamento y corren del artículo 50 hasta el 48, ambos incluidos.

Como es natural, se componen dichas juntas por los electores parroquiales comprendidos por la territorialidad del Departamento de que se trate. Se reunirán el día 8 del mes de septiembre del año de la elección en la cabecera del mencionado Departamento. Y son presididas por la primera autoridad política del mismo.

Dice el artículo 51 que los electores deberán reunirse dos días antes del día 8 de septiembre, con la finalidad de poder examinar las certificaciones que porta cada uno de dichos electores.

Para este propósito, primero se nombran de entre ellos a cuatro escrutadores y a un secretario, quienes examinarán las actas de todos los electores, con excepción de las actas propias. Y para examinar las actas de los mencionados escrutadores y del propio secretario, se nombrará por la junta, en segundo lugar, una comisión de tres personas.

Pues bien, toca a esta junta la competencia de resolver toda clase de dudas y de tachas que puedan presentarse sobre las personas de cada elector, sobre las actas de que son portadores, así como de cualquiera otra cuestión, que tenga que ver con dicha jornada, como evitar que se cometan los delitos de coacción, de soborno, portación de armas, etcétera

Refiriéndose al examen de las actas de cada uno de los electores reunidos, dice el artículo 52, en particular:

Art. 52.En el siguiente día (un día antes de la jornada, es decir, el día 7 de septiembre) se leerán los informes, y si se hallare defecto en las calificaciones o en las calidades de los electores, la junta decidirá en sesión permanente y su resolución se ejecutará sin recurso alguno.

El día señalado, el 8 de septiembre del año de la elección, se procederá a elegir efectivamente a un elector departamental por cada diez mil almas, o por una fracción que pase de cinco mil, etcétera. La votación de los electores parroquiales aquí reunidos ahora se dice que es secreta, o por cédula.

En todo caso, corresponde a la junta resolver los asuntos, las dudas, las cues- 
tiones, que se susciten durante el mismo proceso, así como extender las correspondientes acreditaciones de quienes salgan electos.

c) De la junta de Estado y su competencia

Esta junta se reunirá el primer domingo del mes de octubre en la capital del Estado. Se compondrá de los electores departamentales, bajo la presidencia del gobernador del Estado, según lo dispone el artículo 59.51

Los electores deberán reunirse tres días antes del domingo señalado para poder examinar las certificaciones que cada uno de ellos deben portar. Y para este fin, se nombrarán de entre ellos a dos escrutadores y a un secretario, quienes harán la calificación de las certificaciones de todos los electores, menos de las propias. Para examinar las certificaciones de los dos escrutadores y del secretario se nombra por la junta una comisión de otras tres personas. Luego entra la previsión del artículo 61, que es como sigue:

Art. 61. En el siguiente día se leerán los informes, y si se hallare defecto en las certificaciones o en las calidades de los electores, la junta decidirá en sesión permanente, y su resolución se ejecutará sin recurso por aquella sola vez y para solo aquel efecto. ${ }^{52}$

Llegado el día de la jornada electoral, el domingo primero del mes de octubre, la junta procederá, primero, a la elección de los diputados federales que corresponda; y a continuación elegirá a los diputados y senadores del propio Congreso del Estado.

\section{d) La calificación del congreso}

Como sabemos bien, el proceso electoral culmina en el mismo recito del poder legislativo, en donde los electos diputados y senadores, por seguir citando el ejemplo de Oaxaca, se reúnen en juntas preparatorias, previas a la celebración de la sesión en que se procede a la instalación formal de cada uno de estos dos cuerpos legislativos. Es decir, cada cámara procede a realizar las juntas preparatorias de manera independiente.

Ahora bien, en algunos textos, no existen las juntas preparatorias, ya que se ordena que la calificación de la elección o el examen de credenciales de la elección sea hecho por parte de la llamada Diputación permanente, e incluso por parte del Consejo de gobierno.

${ }^{51}$ Ibidem. p. 187.

52 Ibidem. 
Cuando está previsto que haya juntas preparatorias, en ellas los señores diputados y senadores, si existiere esta cámara, hacen entrega de la respectiva documentación, expedida por la autoridad electoral que lo haya elegido, en donde se acredita que fueron electos siguiendo las formalidades establecidas en la constitución.

Así mismo, durante las sesiones preparatorias, que celebran una y otra Cámara, se nombra de entre los presentes a un presidente, a uno o dos secretarios, según las necesidades del caso, y a dos comisiones especiales, que tienen la finalidad de examinar la documentación entregada por cada uno de los señores diputados y senadores.

e) Conclusión particular de este apartado

Según se puede apreciar, se deja en manos de cada una de estas juntas no sólo la administración de la elección, que en cada caso corresponda, sino también la competencia para resolver cualquier asunto relacionado con ella, sin ningún recurso.

También vemos que cada junta está presidida por una autoridad política, la del lugar, incluyendo al gobernador, que preside la junta del Estado. En los países avanzados en su desarrollo democrático, es normal que el gobierno en turno administre las elecciones sin mayores problemas ni contratiempos

Este mismo sistema de elecciones indirectas, establecido en el respectivo texto constitucional se usaba para la elección de los diputados federales, pues como se recordará, el Presidente mexicano era electo por las legislaturas de los Estados y la H. Cámara de Diputados, votando por diputaciones estatales.

Igualmente recordamos que el sistema de elecciones indirectas en México, con sus convenientes adecuaciones, todavía se aplicó para elegir a don Francisco I. Madero después de la Revolución de 1910.

Cada asamblea se toma la mayor libertad para adecuar el sistema de las elecciones indirectas, usando esta o aquella terminología, manteniendo siempre el régimen de la elección.

Así, en algunos textos se habla de juntas primarias, juntas secundarias y juntas de departamento, tal como sucede en la Constitución de Occidente; mientras que en otros casos, se habla de juntas municipales y juntas de Estado, como leemos en la de Tabasco; o se hala de juntas municipales y juntas de partido, como en la de Tamaulipas; o de asambleas electorales municipales y asambleas electorales de partido, como dice la de Coahuila y Texas.

Ahora bien, el régimen de cómo se debe hacer la elección en cada junta es el mismo en uno y otro texto. 
G) Sobre el régimen parlamentario

Habiéndose declarado vigente el texto gaditano con anterioridad a la reunión de las diferentes asambleas parlamentarias, tanto de carácter general (esto es, los congresos constituyentes mexicanos de 1822-1824) como las asambleas de carácter local, las elecciones para reunir a estas asambleas se hacen de conformidad con dicho texto gaditano, adaptándolo en cada caso, por ejemplo, respecto de la base de población a tomar en cuenta.

Después, cada una de estas asambleas y en relación con su trabajo parlamentario se conduce de conformidad con lo establecido en la misma Constitución de Cádiz, así como de conformidad con alguno de sus reglamentos interiores.

Así, por ejemplo, la Soberana Junta Provisional Gubernativa, cuyos miembros no fueron objeto de elección alguna, sino que fueron nombrados directamente por don Agustín de Iturbide, sí sabemos que se guió por el reglamento interno de las Cortes de Cádiz de 1810. Lo mismo hará el llamado primer Congreso Constituyente Mexicano de 1822, y el también llamado segundo Congreso Constituyente Mexicano de 1824.

Más aún, cuando uno y otro Congreso quisieron elaborar un reglamento propio, para su régimen interno, o bien para el régimen de los congresos ordinarios, lo hicieron siguiendo muy fielmente los modelos gaditanos, como lo explica su servidor en el libro Introducción al federalismo: la formación de poderes de 1824, que hemos venido citando.

Igualmente recomendamos la lectura de nuestro artículo "Algunas consideraciones de carácter histórico sobre el régimen interno del Congreso de la Unión», publicado en la Revista Mexicana de Estudios Parlamentarios del Instituto de Estudios Legislativos de la H. cámara de Diputados, primera época, volumen I, número 2, mayo-agosto de 1991, México.

El mismo régimen han tenido los congresos locales hasta nuestros días, con la salvedad relativa al régimen que regula ahora mismo el sistema de los grupos parlamentarios, que, como sabemos, es de reciente creación.

En suma, las bases de su régimen parlamentario son las mismas que decretaron para sí las Cortes de Cádiz; bases relativas a la organización de su aparato administrativo; bases para el examen y calificación de elecciones, apenas suprimido apenas mediante la reforma al sistema de 1977; bases para su trabajo parlamentario, como nombramiento de comisiones, como procedimiento para discutir y aprobar una ley; como procedimiento para hacer efectiva la responsabilidad de los altos funcionarios, etcétera. 
H) Sobre materia de libertades y derechos

Estamos ante una materia que ha sido poco estudiada por los autores mexicanos, para quienes, por un lado, la Constitución española de Cádiz solamente tuvo breves periodos de vigencia, cada uno de ellos y todos juntos sin la menor importancia; y, por otro lado, la materia de los derechos humanos, como ahora les llamamos, no fue sino apenas tocada de lado por aquellas Cortes, de manera que solamente llama la atención, y no mucha, el decreto sobre libertad de imprenta.

Nada más lejos de la verdad. Para su servidor, la materia de libertades y derechos es la materia más importante para aquellas Cortes, después de la presencia de las tropas francesas en suelo peninsular; es, además, la materia mejor y más ampliamente trabajada. Y, para México, lo mejor que podía recibir de aquellas Cortes. Y quiero insistir en que todo se aceptó y se recibió con muchísimo provecho.

a) Sobre la liberalización de la economía y de la vida social

Están todavía por estudiarse una serie larga y de la mayor importancia de decretos y de órdenes, emitidas por las Cortes de Cádiz, que regulan diferentes libertades y derechos del hombre en sociedad, como dicen los textos neogranadinos.

Por un lado, se trata de disposiciones aisladas unas de otras, que se emiten cuando, en particular, se presenta la necesidad, la oportunidad o la conveniencia de hacerlo; y que, vistas estas disposiciones en su conjunto, representan una interesantísima liberalización de la vida social y económica de los lugares en donde se fueron aplicando, como fue el caso de la Nueva España. Y cada una de estas disposiciones es de tal naturaleza que, una vez emitidas, nunca podrían ser anuladas, debido a su intrínseca bondad.

Por ejemplo, una vez emitido el decreto sobre libertad de imprenta, ¿quién podría derogarlo, como no fuera para reemplazarlo por uno mejor? Tenemos el decreto sobre supresión de la horca, ¿cómo podrían ser derogado, para implantarse de nueva cuenta? También se suprimieron todas las clases de tormentos, ¿cómo podrían derogarse para implantarlos otra vez en una sociedad civilizada?

Pero, por otro lado, se trata de disposiciones que son expresamente declaradas en vigor, no sólo por las colecciones que hemos venido citando, sino también por los mismos textos constitucionales como complementos de la racionalidad y la bondad que muestran dichos textos. Por ejemplo el artículo 84 de la del Estado de Veracruz dice lo siguiente: 
Art. 84. Las leyes existentes continúan en su vigor, siempre que no se opongan al actual sistema, o no bayan sido expresamente derogadas. ${ }^{53}$

Siguiendo con los ejemplos de esta clase de disposiciones libertarias, tenemos el decreto sobre la igualdad de derechos de los habitantes de Ultramar y de los españoles peninsulares, del 15 de octubre de 1810.

Este decreto decía que todos los dominios españoles formaban una y misma monarquía, una misma nación y que por ello, citamos, sus babitantes son iguales en derechos a los de esta península.

Dicho decreto se recoge también como ley vigente en la Colección de Manuel Dublán y José María Lozano, en su tomo primero, página 336. Y fue complementado por otras varias medidas, como por el decreto del 6 de agosto de 1812, sobre abolición de privilegios, (Tomo primero, p.343 y 344). Con todo, debemos decir que aquellas Cortes nunca quisieron declarar la abolición de la esclavitud, como sí lo hace cada una de las constituciones locales mexicanas de ese periodo.

También tenemos el decreto sobre libertad de imprenta, tema que ha sido estudiado por su servidor, a la luz del debate que provocó. ${ }^{54}$ Sobra decir que fue incluido en la Colección de leyes vigentes de Manuel Dublán y José María Lozano, en su tomo primero, en donde, además, se incorpora el Reglamento sobre libertad de imprenta del día 13 de diciembre de 1821 (p.564-567)

Por cierto, la legislación sobre la libertad de imprenta, contemplaba una figura colegiada para su protección, llamada Junta de censura, la cual debía efectivamente recibir las quejas que se pudieran presentar, tanto para proteger el ejercicio de dicho Derecho, como para examinar si un impreso determinado debía o no haber solicitado la licencia previa que, como sabemos, era procedente en materia de dogma, para evitar que los eclesiásticos interfirieran en este ejercicio.

La Junta se componía de nueve individuos, tres de los cuales, debían ser eclesiásticos. En todo caso, su efectiva protección se encomendó siempre al Congreso de la Unión. ${ }^{55}$

Tenemos el decreto de 9 de febrero de 1810 sobre la libertad para sembrar y cultivar cuanto la naturaleza y el arte les proporcionen.

Nada más hermoso como una valiosísima prerrogativa del ser humano, considerado como ser inteligente o racional y ser trabajador y laborioso. Y nada más útil para el hombre que vive en sociedad en esta geografía de la Nueva España,

\footnotetext{
${ }^{53}$ Véase este artículo en Colección de Constituciones de los Estados Unidos Mexicanos, ya citada, tomo III, página 258.

${ }^{54}$ Véase Barragán José, Temas del liberalismo gaditano, ya citado, página 12 y siguientes.

${ }^{55}$ Véase Barragán, José, en Temas del liberalismo gaditano, ya citado, página 3 y siguientes.
} 
hasta entonces sujeta a innumerables prohibiciones y limitaciones en muchas materias de la agricultura y la ganadería, en materia de comercio y de industria; o en materia de pesca, calificadas por don Jacinto Pallares en su libro Derecho Mercantil Mexicano, de absolutas y absurdas.

Pues bien, las Cortes españolas de Cádiz fueron estudiando estos extremos y fueron suprimiendo todas y cada una de esas limitaciones al ejercicio libre de esta clase de derechos. Es decir, el derecho a ejercer libremente cualesquiera de estas actividades y comenzaron aprobando un decreto del 26 de enero de 1811, declarando la libertad de los azogues, que antes estaba estancado, comenta Jacinto Pallares, (Tomo primero, p.186); luego siguió el decreto arriba mencionado, el cual se recoge en la Colección de Manuel Dublán y José María Lozano, (Tomo primero, p.340); y la libertad del buceo de la perla y de la pesca de la ballena, la nutria y el lobo marino, disposición ésta que se encuentra en la página 7 y 8 de la Colección de Galván.

De no menor importancia es el decreto sobre abolición de los señoríos del 6 de agosto de 1811, el cual supuso, por un lado, una verdadera nacionalización del poder económico a favor de la nación, o del Estado; y, por otro lado, convirtió en propietarios a muchísimos poseedores de tierras de señoríos, ya que su artículo IV decía: quedan abolidos los dictados de vasallo y vasallaje, y las prestaciones así reales como personales, que deban su origen a título jurisdiccional, a excepción de las que procedan de contrato libre en uso del sagrado derecho de propiedad. Viene en la página 17 de la Colección de Galván.

Las medidas benéficas de la supresión de los señoríos deben complementarse con la supresión de toda especie de vinculaciones según reza el título del decreto del día 27 de septiembre de 1820, como los mayorazgos, los fideicomisos, los patronatos y cualesquiera otra clase de vinculaciones de bienes raíces, muebles, semovientes, censos, juros, foros o de cualquiera otra naturaleza, los cuales se restituyen abora a la clase de absolutamente libres, en palabras de su artículo $1^{\circ}$., mismo que puede leerse en la Colección de Galván en página 132.

Por ello mismo, tal como lo comenta Pallares, dichas Cortes de Cádiz fueron suprimiendo una a una las diversas prohibiciones que existían, ampliando diríamos ahora nosotros las libertades fundamentales, aunque nada más fuera para liberar la fabricación y la venta de naipes, como lo indica el decreto de 26 de septiembre de 1811, el cual puede ser consultado en el libro de Galván, en la página 20 y se complementa con lo dispuesto por el decreto del día 8 de junio de 1813 Sobre el libre establecimiento de fábricas y ejercicio de cualquier industria útil, de tan solo dos artículos, que decían:

Art. I. Todos los españoles y extranjeros avecindados, o que se avecinden en los pueblos de la Monarquía, podrán libremente establecer fábricas o artefactos de cualquier clase que 
les acomode, sin necesidad de permiso o licencia alguna,, con tal que se sujeten a las reglas de policía adoptadas o que se adopten para salubridad de los mismos pueblos.

Art. II. También podrán ejercer libremente cualquier industria u oficio útil sin necesidad de examen, titulo o incorporación a los gremios respectivos, cuyas ordenanzas se derogan en esta parte.

Son meros ejemplos, pues todavía habría que mencionar otros de igual o mayor importancia, como son los que regulan lo que hoy llamamos derechos de autor: ahí está el decreto del día 10 de junio de 1813 que se intitula Reglas para conservar a los escritores la propiedad de sus obras, mismo que puede leerse en la Colección de Galván en la página 84; o este otro del día 9 de octubre de 1820 asegurando el derecho de propiedad a los que inventen, perfeccionen o introduzcan algún ramo de la industria, el cual puede consultarse en la página 139 de la misma Colección de Galván.

Otros varios decretos tienen un carácter más personal, pero son igualmente liberadores, como la libertad de colegiación para los abogados, reconocida por el decreto del 22 de abril de 1811, el cual puede leerse en la Colección de Galván en la página 8; y la libertad a favor de los oriundos del Africa para ser admitidos en las universidades, seminarios, que es como reza el título del decreto del día 29 de enero de 1812. Se ordena que puedan ser admitidos a las matrículas y grados de las universidades, ser alumnos de los seminarios, tomar el hábito en las comunidades religiosas. a fin de que lleguen a ser cada vez más útiles al Estado.

b) Otras libertades y derechos

Existen otros varios decretos, todos importantes, como el decreto del 22 de abril de 1811, sobre la abolición de la tortura y los apremios. Fue aprobado por unanimidad y con gran solemnidad. La idea era prohibir toda clase de sufrimientos y de molestias a los reos y presos. Puede leerse en la Colección de Dublán y Lozano, p.348 del tomo I.

Esta prohibición fue complementada con otras varias, más específicas y particulares, como por ejemplo, la prohibición de la pena de la horca por decreto del 24 de enero de 1812; como la prohibición de las mitas por el decreto del día 9 de noviembre de 1812; la prohibición de los azotes en las escuelas y colegios por el decreto del día 17 de agosto de 1812; así como la prohibición de azotes sobre las personas de los indígenas por decreto del 8 de septiembre de 1813 . Decretos todos que han sido recogidos en la Colección de Dublán y Lozano, que venimos citando, tomo I. 
c) Derechos, libertades y garantías en las constitucionales locales

Con absoluta independencia de la lista de decretos que hemos mencionado, las constituciones locales, con excepción de la del Estado de Veracruz, reproducen, en muchas ocasiones ampliando el listado, todos y cada uno de los derechos, todas y cada una de las libertades y todas y cada una de las garantías procesales de la Constitución española de Cádiz, incluido el sistema de responsabilidad en que incurren quienes puedan violar dichos derechos, libertades y garantías.

Nos resulta imposible entrar a examinar los pormenores de esta masiva influencia de la Constitución de Cádiz sobre las constituciones locales del periodo de 1824-1827. Con todo, nos es grato remitir al lector, entre otras publicaciones de su servidor, al libro Recepción de los derechos bumanos de la obra de las Cortes de Cádiz en el constitucionalismo local mexicano 1824 -1827, publicado en Guadalajara, México, en el 2007; así como Las garantías procesales de Cádiz en las constituciones locales mexicanas (1824-1827).

\section{d) Sobre el sistema de responsabilidad}

Igualmente es importante examinar el sistema de responsabilidad establecido por las Cortes de Cádiz para hacerla efectiva sobre quienes violen, por un lado, el texto constitucional y, por otro lado, cualquiera de los derechos, libertades y garantías establecidas en dicho texto constitucional.

Este sistema se encuentra regulado en la propia Constitución de Cádiz y pasa íntegramente a cada uno de los textos constitucionales locales de referencia.

Luego, fue regulado en sus pormenores, entre otras disposiciones, por el decreto de 24 de marzo de 1813, que tipifica los delitos en que pueden incurrir los jueces (capítulo primero); así como los demás funcionarios públicos (capítulo segundo); y por el decreto del 17 de abril de 1821 sobre conspiradores, que son todos los que violen precepto alguno de la constitución, o violen algunos de sus contenidos más valiosos, entre los cuales están todas las garantías procesales.

Dicho sistema pasa íntegramente a los textos constitucionales locales mexicanos, así como son declaradas vigentes las normas expedidas por aquellas Cortes de Cádiz, y por las de Madrid de 1820 y 1821 sobre este particular.

Esta materia ha sido estudiada con detenimiento por su servidor en el libro El juicio de responsabilidad en la constitución de 1824, antecedente inmediato del amparo, publicado por la Universidad Nacional Autónoma de México, México 1978. 
e) Sobre el sistema de administración de justicia

Por paradójico que parezca, el sistema de administración de justicia regulado por la Constitución española de Cádiz, pasa a cada una de las constituciones locales, con excepción de la del Estado de Veracruz.

Esto es, en aquellos casos en donde, por entrar en vigor la Constitución de Cádiz, ya se había instalado una Audiencia territorial y estaban instalados los respectivos juzgados, como ya lo hemos ilustrado, primero, se emite la declaración de rehabilitación para que dichas autoridades sigan trabajando como hasta el presente y de conformidad con la legislación vigente.

En segundo lugar, al pasar a la aprobación del respectivo texto constitucional, la asamblea constituyente declara que dicha Audiencia cambie de nombre, para por el de Tribunal Supremo.

$\mathrm{Y}$ en tercer lugar, se incorporan al texto constitucional particular los mismos principios, que se consagran en el texto gaditano bajo los rubros de Administración de justicia en lo general, administración de justicia en lo civil y administración de justicia en lo criminal.

Para corroborarlo, basta comparar los textos, los de ayer de 1824-1827, o los que ahora mismo están en vigor, ya que, como lo comprobará el lector, dicho sistema está conformado por dos instancias fundamentales, la instancia de jueces menores y la instancia de la Audiencia o Tribunal Supremo. Por ello mismo, la norma que se aplica es la del decreto de 9 de octubre de 1812, sobre arreglo de tribunales.

Este decreto en realidad es un reglamento de las audiencias y juzgados de primera instancia, como indica su encabezado. En él, además de las visitas de cárceles, se declararon en vigor los recursos de amparo de la tradición castellana, así como otros varios recursos especiales, regulados en otros cuerpos de leyes peninsulares, tal como se dice en el artículo XII del capítulo segundo.

He aquí el texto de este importante pasaje:

XII.- No debiendo ya instaurarse en primera instancia ante las audiencias los recursos de que algunas han conocido hasta ahora con el nombre de auto ordinario y firmas; todas las personas que en cualquier provincia de la monarquía sean despojadas o perturbadas en la posesión de alguna cosa profana o espiritual, sea eclesiástico, lego o militar el perturbador, acudirán a los jueces letrados de partido para que los restituyan o amparen; y éstos conocerán de los recursos por medio del juicio sumarísimo que corresponda, y aún por el plenario de posesión, si las partes lo promovieren con las apelaciones a la audiencia respectiva en el modo y casos que previene el artículo 43 del capítulo I, reservándose el juicio de propiedad a los jueces competentes siempre que se trate de cosas o personas que gocen de fuero privilegiado. ${ }^{56}$

\footnotetext{
${ }^{56}$ Esta ley se incorpora a la Colección de Dublán y Lozano, tomo I.
} 
Durante el debate de estas materias, se ponderó no sólo la importancia de los recursos mencionados, sino que fueron declarados vigentes, así como otras varias especies de recursos forales.

Se mencionan para Galicia, el auto ordinario o auto gallego; para el reino de Aragón y Valencia, los recursos de firmas posesorias y los recursos de firmas titulares; el recurso de firma y contrafirma; el recurso de aprehensión de bienes para ponerlos bajo protección; los recursos de inventario y de manifestación de personas; para el reino de Castilla, los recursos de amparos posesorios, o interdictos adipiscendae; retinendae, recuperandae y la parte es desde luego amparado o manutenido; y se acepta que otro tenga mejor derecho para pedir la posesión, o para resistiv el amparo. ${ }^{57}$

Se comenta también que estos recursos, por ejemplo en Aragón, en los primeros tiempos se hicieron valer ante el Justicia, ante las Cortes y, posteriormente, ante la Audiencia; en Castilla ante los justicias ordinarios, ante la Chancillería; en Granada, también ante la Chancillería; en Navarra, ante el Consejo.

Se precisa que se trata, ante todo, de otorgar una protección para evitar la violencia, sin perjuicio de que, posteriormente, se hagan valer los respectivos derechos por medio de los juicios correspondientes, interpuestos ante los jueces competentes.

Por regla general, esta clase de recursos se usaban para pedir la protección en materia del derecho de propiedad y de posesión. Sin embargo, también podían usarse para demandar la protección personal, o de sus personas, de sus libertades y de otros varios derechos y libertades:

«... sino que por medio de otro proceso conocido por el nombre de firmas, la Audiencia, a instancia de los oprimidos, o que temen serlo, prohíbe a cualesquier jueces o particulares, eclesiásticos o seculares,, el inquietarlos indebidamente en sus personas, derechos y bienes o en la posesión de ellos, y entiende también y determina sobre esta en el juicio sumarísimo, y en el plenario con la misma o mayor amplitud.» ${ }^{58}$

En otro pasaje del dictamen sobre el Proyecto de arreglo de las Audiencias, se dice:

«Los aragoneses, siempre amantes de su justa libertad, introdujeron estos remedios, con los cuales acudiendo al Tribunal real, y al principio al Justicia de Aragón, conseguían asegurar sus bienes, derechos y personas, libertándose por estos

${ }^{57}$ Esta parte del Dictamen, como ya lo hemos señalado, se puede consultar en nuestro libro Temas del liberalismo gaditano, ya citado, p. 179 y siguientes.

${ }^{58}$ Este comentario se encuentra en el mismo Dictamen, que venimos citando. Véase también, si le es más cómodo al lector, en nuestro libro Temas del liberalismo gaditano, ya citado. 
remedios de la turbación y violencia que les causaban o intentaban causar, no sólo los particulares, sino también los jueces, así seculares como eclesiásticos, por sus injustos y violentos procedimientos.»

Ante las dudas que, con demasiada frecuencia, se formulan sobre estos recursos, he aquí otro pasaje tomado del mismo dictamen:

«Viniendo el recurrente con las calidades prevenidas por fuero, despacha el Tribunal Real el correspondiente amparo, con el que queda libre de toda violencia y perturbación; debiendo obedecer estas provisiones bajo la pena de fractores, mientras se ventila el asunto en el tribunal de donde dimanan, en el cual se conoce no solo en el sumarísimo, sino en el plenario de posesión de cualquier cosa, sea espiritual o profana. Todos los referidos recursos se fundan en la protección que debe dispensar el soberano a sus súbditos contra cualquiera violencia, quienquiera que sea el que la cause.»

Claro está, que hoy en día, a esa estructura tradicional histórica, se le sumaron, las juntas laborales, así como el Tribunal contencioso administrativo. Y, desde luego, ahora los juicios pueden no terminar dentro del territorio de cada Estado, o de cada Audiencia, como decía el texto gaditano, porque se acepta la procedencia de los juicios de amparo, y pueden dilatarse casi tanto como se quiera.

\section{f) Sobre visitas de cárceles}

La legislación sobre visitas de cárceles tiene por objeto la salvaguarda, tanto de la libertad personal como de las garantías procesales, reconocidas a los reos y presos. Se trata de una obligación impuesta a los jueces y a los tribunales, cuya inobservancia implica la comisión de un delito. Nosotros mismos, en el libro Legislación mexicana sobre presos, cárceles y sistemas penitenciarios, publicado en México, en el año de 1976, nos hacemos cargo de esta clase de normas sobre visitas de cárceles.

Aquí, en esta materia, las Cortes fueron muy generosas al disponer que las cárceles no eran una pena, sino el lugar en donde se cumplían las penas; y que no debían servir para molestar a los presos, sino para su custodia. Por ello, debían ser anchas y sanas. Por eso las visitas de cárceles son un instrumento magnífico de protección de la libertad individual y la integridad física.

Existen varias disposiciones sobre las visitas de cárceles: la obligación de los jueces y tribunales de hacerlas se encuentran en el decreto del día 9 de octubre de 1812, cuyo capítulo primero, artículos LVI, LVII, LVIII, LIX, LX y el capítulo segundo, artículo XXIV, las regula con todos los pormenores. 
También existe otro decreto del mismo día 9 de octubre del año de 1812, ordenando que hagan dichas visitas generales de cárceles los prelados y los jueces eclesiásticos; y uno más, de la misma fecha, ordenando lo propio a los tribunales de guerra y marina.

Esta materia de las visitas de cárceles, en mi opinión, como otras muchas garantías todavía sigue en vigor hoy en día, por haber sido incorporada a las respectivas leyes orgánicas del respectivo poder judicial. Pero, hace muchísimos años que no se hace visita alguna, no obstante estar considerado el no hacerlas como delito.

\section{A MODO DE CONCLUSIÓN}

Primero, queremos recordar que ni las Cortes españolas de Cádiz, ni las asambleas constituyentes mexicanas, ni las neogranadinas se propusieron nunca formular una declaración formal completa de derechos y libertades. Y decimos completa, porque todas y cada una de dichas asambleas constituyentes incorporaron a sus respectivos textos, bien un listado de derechos y libertades, bien una especie de declaración formal, que siempre es breve e incompleta.

Esto es, se reconocen, sin limitación alguna todos los derechos, todas las libertades inherentes al ser humano, en cuanto tal, o inherentes al hombre en sociedad, como dicen los textos neogranadinos. Esto es lo que se entiende del debate e, incluso, esto es lo que se dice en algunos textos, como el siguiente, tomado de la Constitución del Estado mexicano de Querétaro:

Art.11. La enumeración de algunos derechos de los queretanos en esta constitución, no podrá alegarse como exclusión de los demás que por la constitución federal y leyes generales les competan.

Este es precisamente el principio que debe prevalecer en esta materia de libertades y derechos humanos, generalizándolo, desde luego, tanto para las Cortes de Cádiz como para las restantes asambleas mexicanas de este mismo período histórico; y universalizándolo, para entender que la enumeración de algunos derechos, no podrá alegarse como exclusión de los demás que pueden estar reconocidos en las leyes, fuera del texto constitucional, o sean inherentes al ser humano, por tratarse de derechos naturales e imprescriptibles, como indica el artículo 8 de esta misma Constitución de Querétaro.

Segundo, respecto de la simpatía que se tiene para con las leyes gaditanas y, en particular para con su texto constitucional, nosotros hemos tomado como referentes importantes, no sólo las declaraciones formales de vigencia, hechas por autoridades mexicanas, sino que también tomamos en cuenta el sentido de jus- 
tificación de dicha vigencia que aparece en los debates, tal como lo vamos a ejemplificar seguidamente a modo de conclusión de este trabajo.

Que nosotros sepamos, hubo un momento en que se propuso abolir la Constitución de Cádiz y se presentó cuando la llamada Junta Nacional Instituyente, compuesta por personalidades previamente nombradas por don Agustín de Iturbide, pasó a discutir en lo general el Proyecto de Reglamento del Imperio mexicano, el cual se presentaba precisamente como una norma que debía sustituir a la Constitución de Cádiz, que estaba en vigor en ese momento, 10 de enero de 1823.

Y este Proyecto, que nunca llegó a aprobarse más que en lo general, se justificaba diciendo en su preámbulo:

«... porque la constitución española es un código peculiar de la nación de que nos hemos emancipado: porque aún respecto de ella ha sido el origen y fomento de las horribles turbulencias y agitaciones políticas en que de presente se halla envuelta: porque la experiencia ha demostrado que sus disposiciones en general son inadaptables a nuestras circunstancias; y porque con tan sólidos fundamentos el Emperador ha manifestado la urgentísima necesidad que tenemos de un reglamento propio...La Junta nacional instituyente acuerda sustituir a la expresada constitución española el reglamento político que sigue...» ${ }^{59}$

Dicho Proyecto lleva las firmas de Antonio J. Valdés, Toribio González y Ramón Martínez de los Ríos y la fecha de 18 de diciembre de 1822.

Don Lorenzo Zavala fue el primero en tomar la palabra, al ponerse a debate dicho Proyecto. Dice que la Junta no tiene legitimidad como para aprobar una constitución, porque yo fui de la opinión que esta Junta nunca podía llamarse cuerpo legislativo. Y luego se pregunta:

«¿Qué derecho tiene la Junta instituyente, ni el gobierno para abolir la constitución española que actualmente nos rige como ley fundamental? ¿Quién puede autorizar legalmente a esta Junta para derribar un código que adoptó la nación por medio de sus representantes y con aprobación del Emperador? Señores, si hemos de seguir principios, si hemos de adoptar doctrinas reconocidas en los pueblos cultos, si queremos a nivelarnos a las naciones civilizadas, si finalmente no queremos ser objeto de la compasión de los sensatos, es preciso convenir que no puede la Junta ni abolir la constitución que nos rige, ni mucho menos sustituirle otra bajo cualquiera denominación que sea.» ${ }^{60}$

${ }^{59}$ Véase el texto completo del Proyecto en Diario de la Junta Nacional Instituyente del Imperio Mexicano, México,1822, a partir de la página 191. La cita viene en la página 191.

${ }^{60} \mathrm{La}$ intervención de Zavala se produce inmediatamente después de presentado el Proyecto a la consideración de los asambleistas y se encuentra en la página 221. 
Después intervino Valdés, principal coordinador de cuatro oradores que había enviado el Emperador para defender dicho Proyecto, para rebatir lo dicho por Zavala, de quien dice estar sorprendido al observar la movilidad de su opinión.

Zavala volvió a tomar la palabra y empieza diciendo que no le parece muy buena lógica la usada por el señor preopinante, porque eso cuando más probaría dice, ligereza y movilidad en mis principios, pero que no quería dejar de contestarle para demostrarle que está muy equivocado...

Y a continuación don José María Bocanegra dijo:

«Que la constitución española está recibida por la nación como ley fundamental del imperio, hasta que se forme la propia, en virtud del Plan de Iguala y Tratado de Córdoba, y de un decreto del Congreso, que inició el gobierno a propuesta del Consejo de Estado, sin que la nación haya expuesto queja alguna contra ella; de suerte que no hay motivo para abolirla...» ${ }^{61}$

Nuevamente tomó la palabra Valdés, argumentando ad personam contra Bocanegra, insistiendo en la legitimidad que, su opinión, tenía dicha Junta.

Más adelante, el señor González Toribio dijo que el proyecto de reglamento no era una constitución, sino que era algo provisional; que la Junta podía discutirlo y, en su caso, aprobarlo, aceptando que efectivamente el Proyecto había tomado muchos principios de dicha Constitución española, porque ésta:

«... contiene los primeros elementos del derecho natural y de gentes combinados con la experiencia de todos los siglos. Estas son las bases de aquella constitución: estas bases son unas mismas en Asia, en América, en Europa y en todo el mundo y estas bases están adaptadas justamente y se han debido adaptar en el reglamento, que no es extraño contenga las doctrinas de la constitución española, pues si no las contuviera ni aún ley se le podría llamar...» ${ }^{62}$

A continuación, tomó la palabra Orantes, para decir:

«Se impugna la constitución española, porque se cree no ser conforme a la voluntad general, y esto me parece una equivocación. Si no llenó el deseo de los americanos, fue porque le faltó liberalismo respecto de ellos, y porque cuanto tiene de bueno nunca lo era ni podía serlo completamente para las Américas; pero esto no era vicio de la constitución, era efecto necesario e irremediable de nuestra dependencia.

Decir que la constitución española es causa de la guerra civil de España, es lo mismo que imputar a nuestra independencia las convulsiones que sufrimos...acu-

\footnotetext{
${ }^{61}$ Véase en el mismo libro ya citado, página 228.

${ }^{62}$ Ibidem, página 231.
} 
sarla de esos males sólo porque se siguieron a su establecimiento, no me parece buen raciocinio, y menos cuando son evidentes y notorias las causas de tales daños.»

Veamos, para terminar, las palabras de Miguel Guridi y Alcocer:

Yo soy amante de la constitución española, por su mérito intrínseco, pues recopila todas las bases del sistema representativo, ya porque tuve el honor de firmarla, habiendo cooperado a su formación. No es pues de extrañar me alarme un reglamento que se exordia improperándola sin razón, y no viene a terminar sino en extractarla.

Es falso que la española lo sea de los españoles con exclusión nuestra, pues se formó también para nosotros, y así como toda la legislación de aquéllos nos sigue rigiendo provisionalmente, a pesar de la independencia, puede también sin que ésta la obste en la misma calidad de provisional, regirnos, como está prevenido, la constitución española.

Que ella haya causado en la Península horribles disturbios, ni es verdadero, cuando éstos han provenido de la malicia de los hombres; ni ese es motivo para desecharla, siendo buena como lo es.

No es tan inadaptable, sino en el punto de las castas, que ya reformó el Plan de Iguala, que hemos jurado.

\section{FUENTE CONSULTADA}

Actas del Congreso constituyente mexicano. Imprenta de Valdés, México 1822.

Aguila Mexicana, periódico de la época, que se comienza a publicar desde el mes de abril de 1823 en la ciudad de México.

Colección de Constituciones de los Estados Unidos Mexicanos. 3 volúmenes. Imprenta de Galván, México, 1828.

Colección de órdenes y decretos expedidos por la Soberana Junta Provisional Gubernativa. Imprenta de Valdés, México 1821.

Colección de los decretos y órdenes de las Cortes españolas, que se reputan vigentes en la República de los Estados Unidos Mexicanos. Imprenta de Galván, México, 1829.

Diario de las discusiones y actas de las Cortes. Imprenta Real, Cádiz 1811.

Diario de sesiones de la Soberana Junta Provisional Gubernativa. Imprenta de Valdés, México 1821.

Diario de la Junta Nacional Instituyente del Imperio Mexicano, México,1822.

Dublan, M. y LozANO, J. M., Legislación mexicana, varios volúmenes. México, 1876. 
Montiel y Duarte, I. A., Derecho Público Mexicano, editado en México en 1871 en cuatro tomos.

Sevilla Andres, D.: Constituciones y otras leyes y proyectos politicos de España. 2 volúmenes, Madrid, 1965.

Title:

ON THE USE IN MEXICO OF THE SPANISH CONSTITUTION OF 1812 CADIZ

Summary:

1. SUBJECT PRESENTATION. 1.1 FIRST TERM, NATIONAL CHARTER 1812. 1.2. PROVISIONS OF THE NATIONAL CHARTER OF APATZINGAN. 1.3. RETURN TO THE OLD REGIME. 1.4. THE NEW FORCE DURING THE LIBERAL TRENNIUM. 1.5. THE ENFORCEMENT ORDER MADE BY THE IGUALA PLAN. 1.6. THE FORCE ENACTED BY PROVISIONAL GOVERNING COMMITMENT SOVEREING. 1.7. THE TERM ORDERED BY THE FIRST NATIONAL CHARTER CONGRESS OF MEXICO. 1.8. THE TERM ORDERED BY THE SECOND NATIONAL CHARTER CONGRESS OF MEXICO. 1.9. THE ORDERED INTO THE STATES. 1.10. LAWS PROCLAIMED IN FORCE. 2. CONSOLIDATION IN THE LOCAL CHARTE. 2.1. STARTING POINT. 2.2. NATIONAL CHARTER REFERED. 2.3. FOLLOWING THE NATIONAL MODEL OF CADIZ. 3. CONCLUSION. 4. REFERENCE.

\section{Resumen:}

En este trabajo se examinan, por un lado, las etapas de vigencia de la constitución española de 1812 en la Nueva España, mientras permanece vinculada al Imperio español y aún después de consumada su independencia en 1821. Se trata de declaraciones de vigencia hechas por las propias autoridades mexicanas, tanto del orden general y federal, como de los 19 Estados que firmaron el Acta de Federación de 1824, consolidándose la organización territorial y política de las provincias, que se transforman en Estados y de las municipalidades. Se destaca la influencia en las constituciones locales mexicanas especialmente en materia electoral, en la organización del respectivo poder judicial y especialmente en materia de libertades públicas y garantías procesales. 


\begin{abstract}
:
In this paper are discussed, on the one hand, the stages of the entry into force of the spanish constitution of 1812 in New Spain, while remains linked to the Spanish Empire and even after consummate their independence in 1821. They are statements of force made by the own Mexican authorities, both of the order and general and federal, as of the 19 States that signed the constitution of 1824, consolidate territorial organization and policy of the provinces, to become States and municipalities. It details the influence in the local mexican constitutions especially in electoral matters, and with the organization of the judiciary power, and especially in the field of civil liberties and guarantees of due process.
\end{abstract}

Palabras clave:

Constitución de Cádiz, influencia, vigencia, Acta de Federación de 1824

Key words:

Constitution of Cadiz, influence, use, Federation Act of 1824 
